\title{
International Capital Markets and Foreign Exchange Risk*
}

\author{
Michael J. Brennan and Yihong $\mathrm{Xia}^{\dagger}$
}

February 17, 2004

${ }^{*}$ We thank Bob Hodrick and Lim Kian Guan for helpful comments. Brennan thanks Lancaster University, and Xia thanks the Singapore Management University, for their hospitality. Xia gratefully acknowledges financial support from the Wharton-SMU Research Center of the Singapore Management University.

${ }^{\dagger}$ Michael Brennan is Emeritus Professor at the Anderson School, UCLA, 110 Westwood Plaza, Los Angeles, CA 90095-1481. Yihong Xia is an assistant professor at the Wharton School of University of Pennsylvania. Corresponding address: Finance Department, The Wharton School, University of Pennsylvania; 2300 Steinberg Hall-Dietrich Hall; Philadelphia, PA 19104-6367. Phone: (215) 898-3004. Fax: (215) 898-6200. E-mail: yxia@wharton.upenn.edu. 


\title{
International Capital Markets and Foreign Exchange Risk
}

\author{
Abstract \\ The relation between the volatilities of pricing kernels associated with different currencies \\ and the volatility of the exchange rate between the currencies is derived under the assumption \\ of integrated capital markets, and the volatilities of the pricing kernels are related to the foreign \\ exchange risk premium. Time series of pricing kernel volatilities are estimated from panel data \\ on bond yields for five major currencies using a parsimonious term structure model that allows \\ for time varying pricing kernel volatilities. The resulting estimates are used to test hypotheses \\ about the relation between the volatilities of the pricing kernels in different currencies and the \\ volatility of the exchange rate. As predicted, time variation in foreign exchange risk premia \\ is found to be related to time variation in both the volatility of the pricing kernels and the \\ volatility of exchange rates: the estimated pricing kernel volatilities can account for the forward \\ premium puzzle in an 'average' sense across exchange rates.
}




\section{International Capital Markets and Foreign Exchange Risk}

\section{Introduction}

The equality under risk neutrality of forward and expected future spot prices has led researchers to explore the relation between forward and future spot prices in bond, commodity, and foreign exchange markets. For example, Fama and Bliss (1987) find that in the bond market, the forwardspot spread, or forward premium, is positively associated with the subsequent change in the spot interest rate, and Fama and French (1987) report similar results for commodities. However, findings in the foreign exchange market have been anomalous; in an influential paper, Fama (1984) reports a negative association between the forward premium in the foreign exchange market and the subsequent change in the spot exchange rate: this unexpected finding has become known as the forward premium puzzle. More recently, Bansal (1997) and Bansal and Dahlquist (2000) have shown that there are important non-linearities in the relation between the forward premium and expected exchange rate changes for certain currency pairs, the sign of the correlation depending on the sign of the interest differential or forward premium. Fama (1984) showed that the forward premium puzzle implies that the variance of the foreign exchange risk premium must exceed the variance in the expected rate of currency depreciation. However, attempts to explain the puzzle with general equilibrium models which assume time-varying uncertainty in fundamentals have met with little success. ${ }^{1}$ Bekaert (1996, p 460) concludes after one such exercise that: "Not a single experiment in all my simulations yields negative correlations (between the forward premium and subsequent changes in the spot exchange rate)". The lack of success of these general equilibrium models has led some researchers to question their underlying rational expectations assumptions. For example, Lewis (1989a, 1989b) proposes rational learning about regime shifts as a solution to the puzzle. ${ }^{2}$ However, the lack of success of general equilibrium models in explaining risk premia is not limited to the foreign exchange market. The existence of the 'equity premium puzzle' ${ }^{3}$ attests to a corresponding failure in the equity market, and the modern approach to bond pricing ${ }^{4}$ typically eschews a general equilibrium approach in favor of an exogenously specified pricing kernel.

\footnotetext{
${ }^{1}$ See, for example, Backus, Gregory and Telmer (1993). Engel (1996) provides an extensive survey of the empirical evidence.

${ }^{2}$ See also Frankel and Froot (1987).

${ }^{3}$ Mehra and Prescott (1985)

${ }^{4}$ See Dai and Singleton (2003) for a summary.
} 
Since the forward premium between two currencies for any given maturity is equal to the interest rate differential for that maturity, it is natural to relate forward premia and exchange rate changes to the term structures of interest rates in the two currencies; several authors, including Backus, Foresi and Telmer (1995, 2001), Bansal (1997) and Nielsen and Saá-Requejo (1993) have taken this approach. All of these papers are based on complete affine models of the term structure of interest rates. These models have the property that the exchange rate risk premium is deterministically related to the interest rates in the two currencies, and Backus et al. (2001) have shown that this property severely limits the ability of these models to capture the forward premium anomaly. The analysis in this paper on the other hand is based on an essentially affine model of the term structure which allows for independent variation in risk premia and interest rates. ${ }^{5}$ This additional model flexibility allows us to obtain estimates of bond market risk premia that are significantly related to the excess returns on foreign currency investment.

The basic theoretical framework relies on the principle that the absence of arbitrage implies, for any numeraire, the existence of a pricing kernel that prices payoffs denominated in that numeraire, and the volatility of the pricing kernel is the maximum Sharpe ratio for returns denominated in that numeraire. In a multiple currency setting, there is a separate pricing kernel for each currency and, in the absence of frictions, a simple relation obtains between the pricing kernels for different currencies and the exchange rates between them. We demonstrate that the exchange rate risk premium between two currencies can be expressed as a function, either of the volatilities of the two pricing kernels, or of the volatility of one of the pricing kernels and the volatility of the exchange rate between the currencies.

In order to estimate the volatilities of the pricing kernels we assume that both the drift and the volatility of each pricing kernel, as well as the corresponding expected rate of inflation, follow simple Markov processes: this assumption gives rise to an essentially affine model of the term structure of interest rates in which yields on default-free zero-coupon nominal bonds are linear functions of the real interest rate, the expected rate of inflation, and the volatility of the pricing kernel. ${ }^{6}$ This allows us to estimate the unobservable volatilities of the pricing kernels by applying a Kalman filter to data on zero-coupon government bond yields and inflation rates.

The bond yield, inflation, and exchange rate data are for the U.S. Dollar (USD), Canadian Dollar (CAD), Deutsche Mark (DM), British Pound (BP), and Japanese Yen (JY) for the period

\footnotetext{
${ }^{5}$ The distinction between an affine model and an essentially affine model is that the compensation for interest rate risk can vary independently of interest rate volatility in an essentially affine model but not in a complete affine model. See Duffee (2002) for more details.

${ }^{6}$ This model was developed in Brennan, Wang and Xia (2003). See also Brennan and Xia (2003).
} 
from January 1985 to May 2002. The term structure model provides a reasonable fit to bond yields for all currencies. However, the prolonged decline in the real interest rate for the JY during the 1990s does not accord well with the mean-reverting assumption underlying the model, and the estimate of the mean reversion parameter for the real interest rate in Japan is close to zero. Exchange rate volatility estimates, which are derived from currency option prices, are available for all currencies against the USD and for the BP and JY against the DM for the shorter period from October 1994 to May $2002 .^{7}$

The no-arbitrage principle implies that the volatility of the pricing kernel associated with one currency is a linear function of the volatility of the pricing kernel associated with a second currency, and of the volatility of the exchange rate between the two currencies. Although our essentially affine framework for estimating the pricing kernel volatility is restrictive, we find strong relations between our estimates of the pricing kernel volatilities for currency pairs and the estimated volatility of the exchange rate between the currencies, which are generally supportive of the implied linear relation.

Our exchange rate data are generally consistent with the forward premium puzzle: regressions of changes in spot rates on the forward premium yield negative coefficient estimates in twelve out of twenty cases, and the precision weighted average coefficient is -0.40 . However, the four DM exchange rates show no evidence of the puzzle: for this currency, all four coefficients are positive and their precision weighted average is 0.59 .

The no-arbitrage principle also implies that the foreign exchange risk premium between two currencies is a linear function of two terms: the volatility of the exchange rate between the currencies, and the product of the exchange rate volatility and the volatility of the domestic pricing kernel. When the return to foreign currency investment is regressed on estimates of these two variables, the estimate of the volatility of the exchange rate is significant in nine out of twelve regressions ${ }^{8}$ and the product term is significant in seven out of the twelve regressions. This is despite the short sample period and the fact that the exchange rate volatility enters both terms in the regression. This evidence supports the view that the predictability in foreign exchange returns is related to general time-variation in risk premia, since the predictability is associated with time-variation in general

\footnotetext{
${ }^{7}$ Measurement errors in the prices of the underlying and the option, as well as the use of inappropriate option pricing models, can create bias in implied volatility estimates. Neely (2003) and Chernov (2002) address the issue of bias in implied volatility forecasts of future volatility. Jorion (1995) reports that, despite their limitations, implied volatility estimates outperform those from GARCH models even with "ex post" parameter estimates.

${ }^{8}$ We use the implied volatility derived from currency options instead of the conditional volatility estimated from a GARCH model. Baillie and Bollerslev (1989, 1990), Bekaert and Hodrick (1993), and Domowitz and Hakkio (1985) find virtually no significant relation between the conditional volatility and the drift of the exchange rate. GARCH estimates of volatility may contain large errors due to limited sample sizes and possible misspecification of the GARCH model.
} 
market risk premia. ${ }^{9}$

Since the implied volatility estimates of exchange rate volatility are available for only certain currency pairs and for a limited time period, we also consider an alternative but equivalent specification of the foreign exchange risk premium, which expresses it as a function of the volatilities of the pricing kernels associated with the two currencies, without involving the exchange rate volatility. We find that the strong association between pricing kernel volatilities and the foreign exchange risk premium remains in the new specification, and extends to the new currency pairs.

In order to determine whether the volatilities of the pricing kernels capture all of the predictable variation in exchange rate risk premia, we also regress changes in the spot exchange rate on the pricing kernel volatilities and the forward-spot rate differential. A likelihood ratio test shows that the pricing kernel volatilities add significant explanatory power in all ten cases. However, in many of the regressions the coefficient of the forward-spot rate spread is far from its theoretical value of unity. Using parentheses to denote estimates that exclude the JY, for which the affine term structure model seems mis-specified: when the USD is the domestic currency, the coefficient ranges from -3.35 $(-0.21)$ to $15.75(15.75)$ and the precision weighted average value is $0.08(0.31)$. For the BP, the range of the coefficient is from -48.18 (-3.38) to 6.51 (6.51) with an average of 1.69 (3.07); for the JY, it is from -48.18 to -2.39 with an average of -5.23 ; for the DM, it is from $-4.42(-2.32)$ to 15.75 (15.75) with an average of $2.53(3.24)$; for $\mathrm{CAD}$, it is from $-3.38(-3.38)$ to $-0.21(-0.21)$ with an average of $-1.20(-0.90)$. The overall precision weighted average is -0.20 (0.76). Thus, while our estimates of pricing kernel volatilities are able to capture a significant portion of the time variation in exchange rate risk premia, they evidently do not catch it all. This is probably due to the restrictive nature of our term structure model and the consequent errors in our estimates of the pricing kernel volatilities.

The rest of the paper is organized as follows. Section 2 derives the theoretical relations between the pricing kernels for different currencies and the exchange rate between them, and relates the foreign exchange risk premium to the pricing kernel and exchange rate volatilities. Section 3 discusses the details of data construction and reports descriptive statistics. Section 4 describes the estimation procedure for the term structure model and discusses the time series of state variable estimates for the different currencies. Section 5 compares the empirical relations between pricing kernel and exchange rate volatility estimates with the theoretical predictions, and assesses the relations between the volatility estimates and the foreign exchange risk premium, and the ability of the volatility estimates to account for the forward premium puzzle. Section 6 summarizes and concludes.

\footnotetext{
${ }^{9}$ In particular, it is associated with risk premia in bond markets which are the source of our estimates of pricing kernel volatility.
} 


\section{Asset Pricing in a Multi-currency Setting}

In the absence of arbitrage, there exists a pricing kernel for any numeraire, that prices all payoffs in terms of that numeraire. Consider a world in which asset prices follow diffusion processes. ${ }^{10}$ Let $m$ and $m^{*}$ denote the (real) pricing kernels corresponding to the domestic and foreign consumption bundles as numeraire, and write the dynamics of these pricing kernels as:

$$
\begin{aligned}
\frac{d m}{m} & =-r(X) d t-\eta(X) d z, \\
\frac{d m^{*}}{m^{*}} & =-r^{*}(X) d t-\eta^{*}(X) d z^{*} .
\end{aligned}
$$

with $m_{0}=m_{0}^{*}=1$. It is understood that the diffusion and drift coefficients of (1) and (2) may depend on a set of unspecified state variables denoted by $X$.

The definition of the pricing kernel implies that any real return process $\frac{d V}{V}$ with volatility $\sigma_{V}$ has an instantaneous expected return given by:

$$
\begin{aligned}
\mathrm{E}\left[\frac{d V}{V}\right] & =-\mathrm{E}\left[\frac{d m}{m}\right]-\operatorname{Cov}\left(\frac{d m}{m}, \frac{d V}{V}\right) \\
& =r d t+\eta \sigma_{V} \rho_{V m}
\end{aligned}
$$

where $\rho_{V m}$ is the correlation between the asset return and the pricing kernel. It then follows that $r\left(r^{*}\right)$ is the domestic (foreign) instantaneous real risk free rate and, since $\left|\rho_{V m}\right| \leq 1, \eta\left(\eta^{*}\right)$, the volatility of the pricing kernel for the domestic (foreign) economy is the maximum Sharpe ratio for returns calculated using the domestic (foreign) consumption basket as numeraire.

Let $s$ denote the real exchange rate expressed in units of domestic purchasing power (units of US consumption basket) per unit of foreign purchasing power (units of UK consumption basket), and write the stochastic process for the exchange rate as:

$$
\frac{d s}{s}=e(X) d t+\sigma_{s}(X) d z_{s}
$$

where again the dependence of the drift and diffusion coefficients on $X$ is to be understood.

The definition of the foreign pricing kernel implies that, for any real foreign gross return between time $t$ and time $t+\tau, x_{t, t+\tau}^{*}$, the following relation holds:

$$
m_{t}^{*}=\mathrm{E}_{t}\left[m_{t+\tau}^{*} x_{t+\tau}^{*}\right]
$$

Moreover, expressing the return on the foreign asset in terms of domestic purchasing power, the

\footnotetext{
${ }^{10}$ See C-f Huang (1985) for sufficient conditions for this setup.
} 
definition of the domestic pricing kernel implies that if the economies are integrated so that foreign real returns can be freely converted into domestic purchasing power:

$$
m_{t}=\mathrm{E}_{t}\left[m_{t+\tau} x_{t+\tau}^{*} \frac{s_{t+\tau}}{s_{t}}\right]
$$

A sufficient condition for (4) and (5) to hold simultaneously is that:

$$
m^{*} \propto m s
$$

and this condition is also necessary if markets are complete. ${ }^{11}$ When markets are complete, both $m$ and $m^{*}$ are unique and one of the three variables $m, m^{*}$ and $s$ is redundant and can be inferred from the other two. If markets are incomplete, there are an infinite number of pricing kernels $m$ and $m^{*}$ satisfying equations (4) and (5), but the minimum-variance pricing kernel for each numeraire derived from the projection of the pricing kernels onto the space of asset returns in that numeraire is unique and satisfies the above conditions. ${ }^{12}$ We will assume that $m$ and $m^{*}$ are the minimum-variance pricing kernels for the domestic and foreign numeraires whenever markets are incomplete.

The relation $m^{*} \propto m s$ implies that:

$$
\frac{d m^{*}}{m^{*}}=\frac{d m}{m}+\frac{d s}{s}+\frac{d m}{m} \frac{d s}{s} .
$$

Substitution from equations (1-3) into equation (6) yields:

$$
-r^{*} d t-\eta^{*} d z^{*}=-r d t+e d t-\eta \sigma_{s} \rho_{s m} d t-\eta d z+\sigma_{s} d z_{s}
$$

Equality of the two stochastic processes requires that their drift and volatility coefficients be the same so that:

$$
\begin{aligned}
\mathrm{E}\left(\frac{d s}{s}\right) & =e d t=\left(r-r^{*}+\eta \sigma_{s} \rho_{s m}\right) d t \\
\left(\eta^{*}\right)^{2} & =\eta^{2}+\sigma_{s}^{2}-2 \eta \sigma_{s} \rho_{s m}
\end{aligned}
$$

Therefore, the stochastic process of $s$ is determined by the joint process of $m$ and $m^{*}$.

Equation (8) expresses the drift of the real exchange rate as the sum of the real interest differential and a risk premium which is equal to the instantaneous covariance of the real exchange rate with the domestic pricing kernel, while equation (9) relates the squared volatility of the two pricing kernels to the variance of the real exchange rate and the covariance of the exchange rate with the domestic

\footnotetext{
${ }^{11}$ See Saá-Requejo (1994) and Backus, Foresi and Telmer (2001).

${ }^{12}$ See Brandt et. al. (2003).
} 
pricing kernel. Note that equation (8) implies that a positive interest differential for the domestic investor $\left(r>r^{*}\right)$ does not necessarily mean that the domestic currency is expected to depreciate (more dollars per pound), since the foreign exchange rate risk may command a negative risk premium $\left(\rho_{s m}<0\right)$.

Combining equations (8) and (9) implies that $e=r-r^{*}+\frac{1}{2} \eta^{2}-\frac{1}{2}\left(\eta^{*}\right)^{2}-\frac{1}{2} \sigma_{s}^{2}$, so that the stochastic process for the log exchange rate may be written as: ${ }^{13}$

$$
d \ln s=\left(r-r^{*}+\frac{1}{2} \eta^{2}-\frac{1}{2}\left(\eta^{*}\right)^{2}\right) d t+\sigma_{s} d z_{s} .
$$

Let $s^{*} \equiv \frac{1}{s}$ denote the real exchange rate expressed in terms of the number of units of foreign purchasing power per unit of domestic purchasing power (e.g., "U.K. goods per unit of U.S. good"); then $d s^{*} / s^{*}=\left(-e+\sigma_{s}^{2}\right) d t-\sigma_{s} d z_{s}$. Symmetry then implies that

$$
(\eta)^{2}=\left(\eta^{*}\right)^{2}+\sigma_{s}^{2}+2 \eta^{*} \sigma_{s} \rho_{s m^{*}}
$$

Combining equations (9) and (11) yields

$$
\sigma_{s}=\rho_{s m} \eta-\rho_{s m^{*}} \eta^{*}
$$

This relation implies that if there is any uncertainty associated with the exchange rate, i.e. $\sigma_{s} \neq 0$, then the exchange rate uncertainty must be priced by either the domestic or the foreign pricing kernel or by both: that is, if $\sigma_{s} \neq 0$ then $\eta^{*} \rho_{s m^{*}} \neq 0$ or $\eta \rho_{s m} \neq 0$, or both. This is a consequence of Siegel's paradox, which says that foreign exchange risk cannot be priced at zero from both domestic and foreign perspective due to Jensen's inequality.

In order to apply this framework to nominal exchange rate data, it is necessary to develop the nominal equivalents of equations (8), (10) and (12). Thus, let $P_{t}\left(P_{t}^{*}\right)$ denote the domestic (foreign) price levels, and assume that the stochastic processes for $P_{t}$ and $P_{t}^{*}$ are of the form:

$$
\frac{d P}{P}=\pi d t+\sigma_{P} d z_{P}
$$

where $\pi$, the expected rate of inflation, will in general depend on the unspecified vector of state variables $X$.

Let $S_{t}$ denote the nominal spot exchange rate expressed in terms of domestic currency per unit of foreign currency (e.g., "dollars per pound"). Note that one unit of the foreign consumption basket,

\footnotetext{
${ }^{13}$ See Bansal (1997) equation (11).
} 
which is equivalent to $P_{t}^{*}$ units of foreign currency, can be exchanged for $s_{t}$ units of the domestic consumption basket, or equivalently for $s_{t} P_{t}$ units of domestic currency. The absence of arbitrage then implies that the real and nominal exchange rates are related to the foreign and domestic price levels by $S_{t} P_{t}^{*}=s_{t} P_{t}$. As shown earlier, the real exchange rate $s_{t}$ is determined by the pricing kernels $m$ and $m^{*}$ via $m^{*} \propto m s$ if the domestic and foreign economies are fully integrated. Therefore, the nominal exchange rate can be directly related to the domestic and foreign pricing kernels:

$$
S_{t}=k \frac{m_{t}^{*}}{m_{t}} \frac{P_{t}}{P_{t}^{*}}, \quad \text { or equivalently, } \quad S_{t} \frac{m_{t}}{P_{t}} \propto \frac{m_{t}^{*}}{P_{t}^{*}},
$$

where $k$ is a constant.

Applying Ito's Lemma to the above equation leads to the following nominal foreign exchange rate process:

$$
\frac{d S}{S}=E d t+\sigma_{S} d z_{S}
$$

where the drift $E d t$ and the volatility $\sigma_{S} d z_{S}$ are given by:

$$
\begin{aligned}
E d t & \equiv\left[R-R^{*}+\eta \sigma_{S} \rho_{S m}+\sigma_{S P}\right] d t \\
\sigma_{S} d z_{S} & =\eta d z_{m}-\eta^{*} d z_{m}^{*}+\sigma_{P} d z_{P}-\sigma_{P}^{*} d z_{P}^{*}
\end{aligned}
$$

$R\left(R^{*}\right)$ is the domestic (foreign) instantaneous nominal risk free rate given by

$$
R \equiv r+\pi-\eta \sigma_{P} \rho_{P m}-\sigma_{P}^{2}
$$

and $\sigma_{x y} \equiv \sigma_{x} \sigma_{y} \rho_{x y}$ denotes the covariance between the innovations to variables $x$ and $y$.

Equation (14) is the nominal counterpart of the real relation (8). The equation expresses the expected change in the nominal exchange rate as the sum of three terms: the nominal interest rate differential, $R-R^{*}$; the covariance of the nominal exchange rate with the domestic price level, $\sigma_{S P}$; and a time varying exchange rate risk premium, $\eta \sigma_{S} \rho_{S m}$, which is equal to the covariance of the nominal exchange rate with the real domestic pricing kernel. A direct implication of this equation is that the exchange rate risk premium, defined as the risk premium on an unhedged position in an investment that is riskless in terms of foreign currency, $\left(R^{*}+E-R\right)=E-\left(R-R^{*}\right)$, is a function of the volatility of the domestic pricing kernel, $\eta$, and the volatility of the nominal exchange rate, $\sigma_{S}:$

$$
E-\left(R-R^{*}\right)=\sigma_{P} \rho_{S P} \sigma_{S}+\rho_{S m}\left(\sigma_{S} \eta\right)
$$

Equation (16) shows that time-variation in the foreign exchange risk premium can arise from 
time variation in the covariance of price changes with the nominal exchange rate, and from time variation in the covariance of the nominal exchange rate with the pricing kernel. In our empirical work we shall treat the volatility of the price level $\sigma_{P}$ and the correlations between the price level and the exchange rate, and between the nominal interest rate and the pricing kernel, $\rho_{S P}$ and $\rho_{S \eta}$, as constant, and seek to explain the variation in the risk premium in terms of variation in the volatility of the exchange rate, $\sigma_{S}$, and of the pricing kernel, $\eta$.

Equation (15) implies the following relation between the variances of the domestic and foreign pricing kernels and the variance of the nominal exchange rate which is the nominal counterpart of equation (9):

$$
\left(\eta^{*}\right)^{2}=\eta^{2}+2 \eta\left(\sigma_{P} \rho_{P m}-\sigma_{S} \rho_{S m}\right)-2 \eta^{*} \sigma_{P^{*}} \rho_{P^{*} m^{*}}+\left[\sigma_{S}^{2}+\sigma_{P}^{2}-2 \sigma_{S P}-\left(\sigma_{P^{*}}\right)^{2}\right] .
$$

Using equations (14) and (17), the stochastic process for the log nominal exchange rate may be written as:

$$
\begin{aligned}
d \ln S & =\left[\left(R-R^{*}\right)+\left(\frac{1}{2} \sigma_{P}^{2}-\frac{1}{2} \sigma_{P^{*}}^{2}\right)+\frac{1}{2} \eta^{2}-\frac{1}{2}\left(\eta^{*}\right)^{2}+\sigma_{P} \rho_{P m} \eta-\sigma_{P^{*}} \rho_{P^{*} m^{*}} \eta^{*}\right] d t \\
& +\sigma_{S} d z_{s}
\end{aligned}
$$

This stochastic process for the nominal exchange rate corresponds to the process for the real exchange rate, (10). The advantage of analyzing the stochastic process for the log exchange rate is that the volatility of the nominal exchange rate cancels out of the drift term, so that the expected change in the log exchange rate depends only on the interest rate differential, which is equal to the forward premium, and the volatilities of domestic and foreign pricing kernels.

Finally let $S^{*} \equiv \frac{1}{S}$ denote the nominal exchange rate expressed in terms of foreign currency per unit of domestic currency. Then symmetry implies that:

$$
\eta^{2}=\left(\eta^{*}\right)^{2}+2 \eta^{*}\left(\sigma_{P^{*}} \rho_{P^{*} m}+\sigma_{S} \rho_{S m^{*}}\right)-2 \eta \sigma_{P} \rho_{P m}+\left[\sigma_{S}^{2}+\sigma_{P^{*}}^{2}+2 \sigma_{S P^{*}}-\sigma_{P}^{2}\right] .
$$

Combining equations (17) and (19) yields the nominal counterpart of equation (12), a linear equation relating the volatilities of the pricing kernels and the volatility of the nominal exchange rate.:

$$
\sigma_{S}=\eta \rho_{S m}-\eta^{*} \rho_{S m^{*}}+\left(\sigma_{P} \rho_{S P}-\sigma_{P^{*}} \rho_{S P^{*}}\right),
$$

Equations (16), (18) and (20) are the basis of our empirical examination of time-variation in 
foreign exchange rate risk premium. In Section 5, we first explore how well the estimates of the volatilities of the foreign and domestic pricing kernels reported in Section 3 satisfy the linear relation (20). Then we test whether time variation in exchange rate risk premia is related to time variation in the volatility of foreign or domestic pricing kernels and the nominal exchange rate volatility, as implied by expression (16). Finally, we examine whether time variation in exchange rate risk premia is related to time variation in the volatilities of the domestic and foreign pricing kernels as specified in equation (18).

In order to carry out this empirical analysis, we must first estimate the volatilities of the pricing kernels associated with the different currencies. The data and the estimation procedure are discussed in the following two sections.

\section{Data Construction and Description}

The basic data used to estimate real interest rates, expected inflation rates, and pricing kernel volatilities (maximum Sharpe ratios) consist of estimated zero coupon bond yields for the second day of each month from January 1985 to May 2002 for the United States, UK, Germany, Canada and Japan. The sample period and the number of countries were limited by the availability of government bond data for a sufficient period of time.

Data on bond prices, coupon rates, and coupon, issue, and redemption dates for all available government bonds outstanding on a given date were taken from Datastream. Most bonds in the U.S., U.K., Canada and Japan pay semi-annual coupons: those that did not were eliminated from the sample. In Germany most bonds pay annual coupons and those that did not were also excluded. Finally, all stripped zero-coupon and floating-rate bonds and bonds that were callable or extended to dates beyond the original redemption dates were excluded.

A cubic spline was fitted to the yields on all the remaining bonds ${ }^{14}$ with maturities up to twenty years for each country and for each month. No extrapolation was used in the estimation, so that the longest possible extracted zero-coupon bond yield for a given month is always less than or equal to the longest maturity bond available for that month. For the U.S., the U.K. and Canada, zero-coupon bond yields for maturities of 6 months, 1, 2, 3, 5, 7 and 10 years were obtained for each month, while for Germany and Japan, the maximum maturity of the zero-coupon bond yields was only

\footnotetext{
${ }^{14}$ Bliss (1996) tests and compares five different methods for estimating the term structure. He finds that the unsmoothed Fama-Bliss method does the best but that differences between this and the cubic spline approach are small. The cubic spline approach seems to be the approach most widely used in empirical studies of U.S. yields.
} 
respectively 7 years and 8 years for each month. The cubic spline approach has been used previously by McCulloch (1975) to fit the U.S. term structure, and by Litzenberger and Rolfo (1984) (LR) to study tax effects on yield curves in different countries. The procedure used here follows LR but ignores capital gains and income tax effects since the model developed in Sections 2 and 3 assumes no taxes or other frictions. ${ }^{15}$

Where possible, the estimated zero-coupon constant maturity bond yields were compared with existing data from other sources. For the U.S., our estimated yield curve was compared with the Fama-Bliss bond yields from CRSP which are only available for maturities of 1,2,3,4 and 5 years up to December 2001, and also with bond yield data provided directly by Bliss for all maturities up to December 2000. Our estimates have very similar sample means and standard deviations to these two datasets. The correlations of bond yields between the two data sets are above 0.95 for maturities of 1, 2, 3, 4 and 5 years but are only 0.7 for 10-year yields. For the U.K. yield curve, our estimates were compared with those published by the Bank of England for the same sample period for maturities of $1,2,3,5,7,10$ and 15 years: the correlations are all above 0.9 , but the sample means of our estimates are slightly higher. Since the data from the Bank of England are available for the whole sample period, we used this dataset for estimating the U.K. state variables.

Table 1 reports summary statistics for the estimated zero-coupon bond yields for the different currencies. The yield curves for USD, CAD, JY and DM are on average upward-sloping. For example, the average zero coupon yield for the USD increases from $6.07 \%$ per year for the six-month bond to $7.41 \%$ for the ten-year bond. The sample standard deviation decreases with maturity, from $1.64 \%$ for the six-month bond to $0.82 \%$ for the ten-year bond. On the other hand, the average yield curve for the BP is slightly hump-shaped and almost flat: increasing from $8.02 \%$ for the one-year bond to $8.14 \%$ for the seven-year bond and then decreasing to $7.88 \%$ for the 15 -year bond. The sample standard deviation also decreases slightly with maturity. Overall, JY bonds have the lowest average yields at around 3-4\% while the BP has the highest average yields at around $8 \%$.

All bond yields are highly persistent with first order autocorrelation of 0.98 or above. Yields for different maturities are also highly correlated, particularly for nearby maturities. The shortest and the longest maturity bond yields have a correlation of 0.74 for the USD, 0.80 for the BP, 0.87 for the $\mathrm{CAD}$ and 0.63 for the DM. Note that for the JY the 6-month and 8-year yields have a correlation of 0.96 , and the correlations between other yields are even higher, suggesting that either a single

\footnotetext{
${ }^{15}$ We also estimated the term structure by specifying a capital gain tax rate of 0 and an income tax rate of $33 \%$. The estimated after yield curve was highly correlated with the before tax curve but with lower sample means. LR found that the minimum absolute standard error of estimate does not vary much with the assumed capital gains tax rate.
} 
factor model may capture the dynamics of the JY term structure, or more plausibly, that the level of rates in Japan has shifted down by so much that the slope effects appear small in comparison.

Table 1 also reports summary statistics for the monthly inflation rates and the excess returns for the equity markets of the countries corresponding to each currency. Inflation rates were calculated from Consumer Price Index data obtained from Datastream and the equity market excess returns were calculated from the total market index returns and treasury bill rates also obtained from Datastream. For our sample period the estimate of the equity premium for Japan is only 1.7\%, although the estimate doubles if the data from 1980 to 1985 are included. On the other hand, the U.S. equity premium estimate during this period is almost $10 \%$, reflecting the bull market of the 1990s. Average inflation rates range from a low of only $0.84 \%$ per year in Japan to a high of $3.8 \%$ in the U.K.

Spot and one month forward exchange rates against the USD as well as the one-month Treasury Bill rates were also taken from Datastream. Cross-rates between currencies other than the USD were calculated by taking ratios of USD exchange rates. Since one-month Treasury Bill rates for the JY are only available starting from December 1993, one-month bill rates from the Bank of Japan were used for the earlier period.

Finally, the volatilities of the exchange rates of the USD for the BP, DM, ${ }^{16} \mathrm{JY}$ and CAD, and the volatilities of the exchange rates of the DM for the BP and the JY were taken as the 1 month implied volatilities calculated from over the counter (OTC) foreign exchange options on the last day of each month and published on the website of the Federal Reserve Bank of New York; the average of the bid and ask implied volatility was used. These data were available only for the period October 1994 to May 2002.

Table 2 reports summary statistics on foreign exchange rates against the USD, and the interest rates used for each of the currencies. Consistent with previous studies, changes in spot rates for all four country-pairs are highly volatile and have very low autocorrelation. The monthly volatility ranges from $1.37 \%$ for CAD to $3.74 \%$ for JY. The mean implied one-month volatilities on a monthly basis range from $1.67 \%$ per year for the CAD to $3.46 \%$ for JY. The autocorrelation of the changes in spot rates is negative for the $\mathrm{CAD}$ and $\mathrm{DM}$ and positive for the $\mathrm{BP}$ and $\mathrm{JY}$, but in all cases the absolute value of the autocorrelation is less than 0.1. In contrast, forward premia exhibit low volatility and much higher autocorrelation: for example, the forward premium for the BP has a monthly volatility of only $0.21 \%$ but an autocorrelation of 0.74 .

\footnotetext{
${ }^{16}$ The implied volatility of the DM against USD, JY or BP was replaced by the corresponding implied volatilities for the Euro starting from January 1999.
} 
Table 3 reports similar summary statistics for foreign exchange cross-rates. The volatility is lowest for the USD-CAD (1.4\% per month) and DM-BP (2.5\%) exchange rates; the volatilities of all other rates are in excess of $3 \%$ per month. The implied foreign exchange volatility data are available only for the $\mathrm{BP} / \mathrm{DM}$ and $\mathrm{DM} / \mathrm{JY}$ exchange rates and their mean implied volatilities on a monthly basis are $2.45 \%$ and $3.46 \%$ respectively. Similar to the USD exchange rates, autocorrelations of changes in the spot cross-rates are all less than 0.11 , while the one-month forward premia have volatilities of the order of 20 to 30 basis points per month and autocorrelations as high as 0.82 .

\section{State Variable Estimates}

In order to estimate the parameters of the pricing kernel process for each country from panel data on bond yields, it is necessary to place some further structure on the dynamics of the pricing kernel and the inflation rate. We follow Brennan, Wang and Xia (2003) (BWX) in assuming that the real interest rate, $r$, and the maximum Sharpe ratio, $\eta$, follow Ornstein-Uhlenbeck processes, so that the stochastic process for the pricing kernel may be written as:

$$
\begin{aligned}
\frac{d m}{m} & =-r d t-\eta d z_{m} \\
d r & =\kappa_{r}(\bar{r}-r) d t+\sigma_{r} d z_{r} \\
d \eta & =\kappa_{\eta}(\bar{\eta}-\eta) d t+\sigma_{\eta} d z_{\eta}
\end{aligned}
$$

The expected rate of inflation, $\pi$, is also assumed to follow an Ornstein-Uhlenbeck process:

$$
\frac{d \pi}{\pi}=\kappa_{\pi}(\bar{\pi}-\pi) d t+\sigma_{\pi} d z_{\pi} .
$$

Under these assumptions, BWX show that the nominal yield on a zero-coupon (default-free) bond of maturity $\tau$ is a linear function of the state variables, $r, \pi$, and $\eta$ :

$$
-\frac{\ln N}{\tau}=-\frac{\widehat{A}(\tau)}{\tau}+\frac{B(\tau)}{\tau} r+\frac{C(\tau)}{\tau} \pi+\frac{\widehat{D}(\tau)}{\tau} \eta
$$

where the coefficients, $\widehat{A}(\tau), B(\tau), C(\tau)$ and $\widehat{D}(\tau)$ are functions of the parameters of the joint stochastic process for the pricing kernel $(21,22,23)$, realized inflation (13), and the expected rate of inflation (24).

In principle, it is possible to estimate the parameters of the system $(21$ - 24) by Maximum Likelihood using equation (25) and yields on three bonds of different maturities. However, the choice of bonds to use in the estimation is arbitrary, and there is no guarantee that the estimates 
will be consistent with the yields of other bonds. Therefore, to minimize the consequences of possible model mis-specification and measurement errors in the fitted bond yield data, we allow for errors in the pricing of individual bonds and use a Kalman filter to estimate the time series of the unobservable state variables $r, \pi$ and $\eta$, and their dynamics, from data on bond yields.

In summary, there are three transition equations for the unobserved state variables, $r, \eta$, and $\pi$, that are the discrete time versions of equations (22), (23), and (24). There are $n+1$ observation equations based on the yields at time $t, y_{\tau_{j}, t}$, on bonds with maturities $\tau_{j}, j=1, \cdots, n$. The first $n$ observation equations are derived from equation (25) by the addition of measurement errors, $\epsilon_{\tau_{j}}$ :

$$
y_{\tau_{j}, t} \equiv-\frac{\ln N\left(t, t+\tau_{j}\right)}{\tau_{j}}=-\frac{\widehat{A}\left(t, \tau_{j}\right)}{\tau_{j}}+\frac{B\left(\tau_{j}\right)}{\tau_{j}} r_{t}+\frac{C\left(\tau_{j}\right)}{\tau_{j}} \pi_{t}+\frac{\widehat{D}(\tau)}{\tau} \eta_{t}+\epsilon_{\tau_{j}}(t) .
$$

The last observation equation is based on the realized inflation rate at time $t$ :

$$
\frac{\Delta P}{P}=\pi \Delta t+\epsilon_{P}(t)
$$

This final observation equation is used to identify $r$ and $\pi$ which enter the bond yield equation (26) symmetrically.

The measurement errors, $\epsilon_{\tau_{j}}(t)$, are assumed to be serially and cross-sectionally uncorrelated, and to be uncorrelated with the innovations in the transition equations. To reduce the number of parameters to be estimated, the variance of the yield measurement errors was assumed to be of the form: $\sigma^{2}\left(\epsilon_{\tau_{j}}\right)=\sigma_{b}^{2}$ where $\sigma_{b}$ is a single parameter to be estimated. This is equivalent to the assumption that the measurement error variance of the log price of the bonds is proportional to the bond maturity. ${ }^{17}$ In addition, it is assumed that the errors in the observation equations are uncorrelated with the innovations of the state variables, i.e., $\rho_{i r}=0, \rho_{i \pi}=0$ and $\rho_{i \eta}=0$ $\left(i=\epsilon_{1}, \cdots, \epsilon_{n}\right.$, and $\left.\epsilon_{P}\right)$.

The long run means of the state variables were set exogenously to facilitate identification and estimation. More specifically, $\bar{\pi}$ for each country was set equal to the sample mean of the CPI inflation rate, which is $3 \%$ for the U.S., $3.8 \%$ for the U.K., $2.8 \%$ for Canada, $2 \%$ for Germany and $1 \%$ for Japan; $\bar{r}$ was set equal to the difference between the sample means of the one-month Treasury bill rate and the CPI inflation rate, which is $2.6 \%$ for the U.S., $4.6 \%$ for the U.K., $4 \%$ for Canada, $3 \%$ for Germany and $2.5 \%$ for Japan; ${ }^{18}$ and $\bar{\eta}$ was set equal to 1.2 times the sample mean of the country's

\footnotetext{
${ }^{17} \mathrm{BWX}$ estimate the system by assuming that $\sigma^{2}\left(\epsilon_{\tau_{j}}\right)=\sigma_{b}^{2} / \tau_{j}$ so that the measurement error variance of the log price is independent of maturity.

${ }^{18}$ Strictly speaking, $r=R-\pi+\eta \sigma_{P} \rho_{P m}+\sigma_{P}^{2}$ in our model. Since we impose $\rho_{P m}=0$ in the estimation and $\sigma_{P}^{2}$ is negligible, we use $\bar{r} \approx \bar{R}-\bar{\pi}$ to derive the long run mean of the real interest rate.
} 
equity market Sharpe ratio, which is 0.62 for the U.S., 0.58 for the U.K., 0.44 for Canada, 0.46 for Germany, 0.21 for Japan. ${ }^{19} \bar{\eta}$ was set $20 \%$ higher than the realized equity market Sharpe ratio to allow for the fact that the equity market is only one component of the investment opportunity set. Note that for any asset $i$, only the product $\rho_{i m} \eta$ is identified in the estimation - therefore errors in the predetermined values of $\bar{\eta}$ will be offset by errors in the estimated correlations. On the other hand, when we relate $\eta$ to foreign exchange risk premia in Section 5, we must acknowledge that our estimates of $\eta$ for any currency are empirically identified only up to a multiplicative constant, so that no restrictions can be placed on the magnitudes of the coefficients of $\eta$. Finally, $\sigma_{\epsilon_{P}}$ was set to the sample standard deviation of realized CPI inflation rates and $\rho_{m P}$ was set to zero to reduce the number of parameters to be estimated.

Table 4 reports the parameter estimates and their asymptotic $t$-ratios for each of the five countries. In all countries, $\sigma_{b}$, the standard error of the measurement error is highly significant, falling in the range of $18-48$ basis points, which is comparable to values found for previous studies of the U.S. term structure.

For all countries except the U.S. ${ }^{20} \sigma_{r}$, the volatility of the real interest rate innovation, is in the range of $63-92$ basis points per year; for the U.S. on the other hand it is 277 basis points. The high volatility of $r$ in the U.S. is offset by strong mean reversion: the estimate of $\kappa_{r}$ is more than twice as high for the U.S. (0.290) as for the next highest country, the U.K., and implies a half life for innovations of about 2.4 years, as compared with almost 5 years in the U.K., almost 6 years in Canada, and more than 10 years in Germany where the mean reversion parameter is not significant. ${ }^{21}$ As we shall see below, there is evidence of mean reversion in the estimates of $r$ for all these countries. For Japan on the other hand, the estimated value of $r$ declines fairly steadily from 1990 so that there is little evidence of mean reversion in this sample period. It is then not surprising to find the estimate of $\kappa_{r}$ close to zero and insignificant; the Ornstein-Uhlenbeck assumption clearly fails to capture the behavior of the real interest rate in Japan during this sample period. The

\footnotetext{
${ }^{19}$ Note that the sample means of the ex post equity market Sharpe ratios and the Treasury bill rates reported here differ from those reported in Tables 1 and 2, because these means are calculated using data starting from January 1980 instead of January 1985. The longer sample period was chosen to improve the efficiency of the estimates for $\bar{r}, \bar{\pi}$ and $\bar{\eta}$. The estimates for $\bar{r}, \bar{\pi}$ and $\bar{\eta}$ are similar in the long and the shorter sample for Canada, the U.K. and Germany. The estimates of $\bar{r}$ and $\bar{\pi}$ for Japan and U.S. are also similar but the estimates of $\bar{\eta}$ are significantly different in the two samples. The estimates based on the sample starting from January 1985 are $\bar{\eta}=0.80$ for the U.S. and 0.10 for Japan.

${ }^{20}$ Note that the CPI index, and therefore the real interest rate also, are defined for country-currency pairs since, for example the U.S./USD real interest rate is the difference between the USD nominal interest rate and the U.S. CPI which relates to prices in the U.S. denominated in USD.

${ }^{21}$ The estimates of $\kappa_{r}\left(\sigma_{r}\right)$ for the U.S of $0.290(2.77 \%)$ compare with values of $0.069(0.966 \%)$ reported by Brennan and Xia (2003) for the (similar) sample period 1985-2002 and by Brennan, Wang and Xia (2003) of 0.074 (1.11\%) for the period 1952-2000; the large differences reflect the difficulty of achieving convergence in the Kalman filter algorithm.
} 
estimated correlation between innovations in the real interest rate and the pricing kernel, $\rho_{r m}$, is negative and highly significant for all five currencies, so that there is a significant real interest rate risk premium and long term bonds command a positive premium in all five currencies.

The estimated volatilities of innovations in expected inflation rates are highly significant and are in the range of 74 to 115 basis points except for Japan where the point estimate of 40 basis points is not significant. The estimates of $\kappa_{\pi}$ are very small and insignificant for the Anglo-Saxon countries, U.S., UK and Canada, but the estimate for Germany is much larger and significant, perhaps reflecting the strong anti-inflationary bias of the Bundesbank. The estimates for the AngloSaxon countries are consistent with previous findings that expected inflation follows close to a random walk. We place little weight on the estimate for Japan since it is clear that during the sample period expected inflation, like the real interest rate, does not conform to the $\mathrm{O}-\mathrm{U}$ assumption underlying the estimation. Finally, $\rho_{\pi m}$ is not significant for any country so that there is no evidence of a risk premium associated with expected inflation.

The point estimate of the volatility of the $\eta$ process, $\sigma_{\eta}$ (i.e., the innovation volatility for $\eta$ ), is in the range of 0.19 to 0.28 for all currencies except the JY where it is only 0.06 - we conjecture that this reflects the generally poor fit of the model to JY yields during this sample period. The point estimate is highly significant only for the BP; the lack of significance and the point estimate of 0.193 for the USD are a little surprising, since the stochastic nature of risk premia in the U.S. has been widely documented, and Brennan, Wang and Xia (2003) and Brennan and Xia (2003) report estimates of $\sigma_{\eta}$ of 0.424 and 0.301 for the periods 1952-2000 and 1983-2000, and these are highly significant. Just as for the real interest rate, the estimate of the mean-reversion parameter, $\kappa_{\eta}$, is highest for the USD and lowest for the DM and JY for which the model does not fit so well. ${ }^{22}$ The half life of innovations in $\eta$ is almost 9.5 years for the $\mathrm{CAD}$, around 6.7 years for the $\mathrm{BP}$, and about 2.4 years for the USD. Finally, $\rho_{\eta m}$, is positive and significant for all currencies except the JY for which, as mentioned, the model does not fit well. It is interesting to note that, with the exception of the JY, the signs of $\rho_{r m}$ and $\rho_{\eta m}$ are opposite and are consistent across currencies, so that the risk premia for these fundamental investment opportunity set risks are priced in a consistent fashion across currencies.

In summary, the estimation results display an encouraging consistency across currencies/countries except for Japan and the JY where the post-bubble economy has not conformed well to the model assumptions about the real interest rate or inflation.

\footnotetext{
${ }^{22}$ The maximized likelihood is lowest for these two countries.
} 
Table 5 reports summary statistics on the time series of the estimated state variables, $r, \pi$ and $\eta$, that are obtained from the Kalman filter for each of the currencies. Note first that the sample mean of a state variable estimate reported in Table 5 may be quite different from the pre-set long run mean reported in Table 3, because the Kalman filter trades off the model fit in time series (ideally, the parameters of the estimated stochastic processes of the state variables correspond to the dynamics of the estimated state variables) and in the cross-sectional prediction of yields on bonds of different maturities. Particularly noticeable are the sample means for $\hat{\eta}$ of 0.145 for the USD and 0.754 for the CAD as compared with our preset estimates of $\bar{\eta}$ of 0.62 and 0.44 respectively. The standard deviation of the estimated real interest rates, ranging from 1.5\% per year for German Mark to $2.7 \%$ for Canadian Dollar, is slightly smaller than those of their respective one-month Treasury bill rates except for the U.S. The standard deviation for the $\eta$ series ranges from 0.19 for Japanese Yen to 0.94 for Canadian Dollar, indicating a large variation in the volatility of the pricing kernel. The autocorrelation for all series is above 0.96 , indicating high persistence in all state variable estimates. This is inconsistent with the few large $\kappa$ estimates reported in Table 3 and again is due to the competing demands of fitting the time series and cross-section of yields using a parsimonious model that may be mis-specified.

The state variable estimates are plotted in Figures 1 to 3 . The time series of real interest rate estimates shown in Figure 1 display considerable volatility for all five currencies, ranging in all cases from a high of between 6 and $8 \%$ to a low of between 0 and minus $2 \%$. All the series except that for Japan display strong mean reversion. While there are common elements in the series, country specific factors are clearly relevant also. Thus, while the patterns for U.S. and Canadian rates are broadly similar after 1990, the U.S. rate drops steeply from about $8 \%$ in the early part of the sample period while the Canadian rate is rising sharply from an initial value of around $2 \%$. The U.K. rate generally tracks the U.S. rate after about 1985, but with a lag: the rates in both countries rise strongly in the late 1990s only to fall after 2000 with the decline in stock markets. The German rate displays a broadly similar pattern, but with a period of elevated rates following German reunification in 1990 and with an earlier decline towards the end of the 1990s reflecting the sluggishness of the German economy during this period. The Japanese interest rate shows the most anomalous pattern, declining almost monotonically from around $5 \%$ in 1990 to minus $2 \%$ by the end of the sample period.

Figure 2 plots the time series of expected inflation estimates for the period of January 1985 to May 2002. The expected inflation estimates for U.S., Japan and Germany exhibit much lower volatility than the real interest rates: they vary only from around $0.5 \%$ to around $4 \%$. On the other 
hand, the estimated rate of inflation for the U.K. moved around in a tight range between $3 \%$ to $6 \%$ until 1997 when it fell rapidly to below zero and then moved up to less than $2 \%$; expected inflation in Canada has long swings in the much larger range of $0.5 \%$ to over $7 \%$.

Figure 3 plots the time series of estimated pricing kernel volatilities or the maximum Sharpe ratios for the five currencies. ${ }^{23}$ The Sharpe ratios for the USD, BP, and DM all reach their lows at the peak of the stock market boom in the 1999-2000 period, the USD decline starting around 1993, the BP decline around 1995, and the DM decline around 1996. The ratios for all three currencies rise rapidly towards the end of the sample period. The CAD and JY Sharpe ratios also decline in the second half of the 1990s, but not so dramatically as for the other three currencies. For both the CAD and JY, the lows (in both cases below zero) are reached in 1990. In the first half of the 1990s Sharpe ratios for all currencies are generally high and increasing. ${ }^{24}$ Finally, in contrast to the unrelated movements in the real interest rates in Canada and the U.S. up to 1990, the Sharpe ratios for the corresponding currencies display strong comovement, initially rising sharply and then entering a long period of decline from 1986 to $2000 .{ }^{25}$

In results not reported here, vector autoregressions were run separately for $r, \pi$, and $\eta$ across the five countries/currencies. ${ }^{26}$ For the real interest rate, feedback effects were found between Germany and the U.K. and from the U.S. to Canada. For the Sharpe ratio, feedback effects were found between the CAD and the USD and between the DM and JY. In addition, the DM ratio was influenced by the lagged $\mathrm{BP}$ ratio and the $\mathrm{CAD}$ ratio was affected by the lagged ratios for all other currencies. The correlations between the real interest rate innovations in all countries are positive, the highest correlations being between Canada and the U.S. (0.48) and Germany and the U.K. (0.44); the next highest correlation is between Germany and Japan (0.38). The correlations between the Sharpe ratio innovations for all currencies are also positive, once again the highest correlations being between the CAD and the USD (0.54) and between the DM and the BP (0.41), all other correlations being considerably smaller. These results are consistent with the hypothesis that geographical proximity and trade relations are associated with common shocks to real interest rates, and with our finding that the volatilities of the exchange rates between the corresponding currency pairs were the lowest.

\footnotetext{
${ }^{23}$ The (absolute value of) the volatility of the pricing kernel defines the maximum Sharpe ratio for returns denominated in a particular currency.

${ }^{24}$ This is consistent with Bekaert and Hodrick (1992), who report large Hansen-Jagannathan bounds for the pricing kernel volatility inferred from foreign exchange and equity returns.

${ }^{25}$ Ilmanen (1995) reports very high correlations between the estimated excess returns on bonds in different currencies that are obtained by projecting the excess returns on the bonds on a common set of instruments.

${ }^{26}$ Strictly speaking, the VAR specification is inconsistent with the parsimonious Ornstein-Uhlenbeck assumption that we have made about the state variable dynamics.
} 


\section{Empirical Results}

We consider first whether our estimated pricing kernel volatilities are consistent with the linear relation between the volatility of domestic and foreign real pricing kernels and the volatility of the nominal exchange rate specified in equation (20). Since $\eta^{*}$ and $\eta$ are highly autocorrelated, a simple regression would yield spurious results. ${ }^{27}$ Therefore we estimate a cointegrating regression between the estimated pricing kernel volatilities and the implied volatility of the exchange rate. Currency option prices from which the implied volatilities are computed are only available for currencies against the USD and the BP-DM, DM-JY pairs, and even for these exchange rates only for the period from October 1994 to May 2002, and the estimation is based on this sample.

The results of the cointegrating regressions which are reported in Table 6 show that the volatility of the foreign pricing kernel is strongly related to the volatilities of both the domestic pricing kernel and the exchange rate. For all currency pairs except the BP-DM pair, the exchange rate volatility is highly significant, ${ }^{28}$ and for each currency pair the volatility of the domestic pricing kernel is significantly related to the volatility of the foreign pricing kernel in at least one of the two regressions.

In order to assess the relation for a wider range of country pairs and over a longer time period, changes in the foreign pricing kernel volatilities were regressed on changes in the domestic pricing kernel volatilities without including the exchange rate volatility in the regression. In results that are not reported here, the relation was found to be weak in the period from January 1985 to September 1994: $\bar{R}^{2}$ all less than $10 \%$ and only three out of twenty currency pairs with significant (at $5 \%$ level) coefficient estimates. In contrast, the coefficient estimates for the sub-period from October 1994 to May 2002 were highly significant except for three currency pairs, all of which involve the JY: the $\bar{R}^{2}$ 's all above $20 \%$ except for those involving JY. For example, the $\bar{R}^{2}$ for the DM-USD regression improved from zero in the first sub-period to around $27 \%$ in the second sub-period while for the DM-BP regression it improved from $5 \%$ to over $40 \%$. Even for regressions involving the JY, the goodness of fit also improved. For example, $\bar{R}^{2}$ for the BP-JY regression rose from only $1.8 \%$ to over $16 \%$. The much stronger results in the second sub period are consistent with a significant improvement in market integration over time. For the whole period, as well as for the two subperiods, the regressions involving the JY always have the the weakest regression results. While this is consistent with the finding of Brandt, Cochrane and Santa-Clara (2002) that their international

\footnotetext{
${ }^{27}$ See Chapter 18 of Hamilton (1994) for detailed discussions. Roll and Yan (2000) discuss this problem in the context of the forward premium puzzle.

${ }^{28}$ Given that the implied volatility may be a biased estimate of the true volatility, the point estimates and standard errors should be interpreted with caution.
} 
risk sharing index is lowest for Japan, it also seems likely that the poor fit of the term structure model to JY yields, and corresponding errors in the JY estimates of $\eta$, are responsible.

In summary, with the exception of JY, we have found strong relations between the volatilities of the pricing kernels estimated for the different currencies: the relation is stronger in the later sub-period and is improved by including a measure of exchange rate volatility as equation (20) predicts.

In order to verify the presence of the forward premium puzzle in our data, a cointegrating regression was estimated between the one-month change in the $\log$ of the spot exchange rate and the difference between the log of the one-month forward and the log of the spot exchange rate:

$$
\ln S_{i, j, t+\Delta}-\ln S_{i, j, t}=c_{0}+c_{1}\left(\ln F_{i, j, t, \Delta}-\ln S_{i, j, t}\right),
$$

where $\Delta=1 / 12$ is one month, and $S_{i, j, t}$ and $F_{i, j, t, \Delta}$ denote the spot and $\Delta$-period (one-month) forward exchange rates between currencies $i$ and $j$ at time $t$ measured in units of currency $i$ per unit of currency $j$. The estimated value of $c_{1}$, reported in Table 7 , is negative in twelve out of twenty regressions; the precision-weighted average of the estimates is -0.40 . This is consistent with previous evidence on the forward premium puzzle. However, the four DM exchange rates show no evidence of the puzzle: all four coefficients are positive and their precision-weighted average is 0.59.

Our model of time-variation in the volatility of the pricing kernel implies that the above regression is mis-specified since it ignores time-variation in the risk premium. The discrete time equivalent of equation (14) implies that the $\Delta$ period expected currency appreciation, $E_{t} \equiv\left(\mathrm{E}\left[S_{t+\Delta}\right]-S_{t}\right) / S_{t}$, is related to the corresponding interest rate differential, $\left(R_{t}^{*}-R_{t}\right) \Delta$, the volatility of the domestic pricing kernel, $\eta \Delta$, and the volatility of the exchange rate, $\sigma_{S} \Delta$. Covered interest rate parity implies that the interest rate differential is equal to the $\Delta$-period forward premium, $\left(R_{t}-R_{t}^{*}\right) \Delta=$ $\left(F_{t, \Delta}-S_{t}\right) / S_{t}$, so that the discrete time equivalent of equation (14) can be written as:

$$
\frac{E\left[S_{t+\Delta}\right]-F_{t, \Delta}}{S_{t}}=\left[\rho_{S m} \eta \sigma_{S}+\sigma_{P} \rho_{S P} \sigma_{S}\right] \Delta
$$

where $\Delta=\frac{1}{12}$ if the time step is one month.

Equation (27) implies the following stochastic relation between the excess return on foreign currency investment, exchange rate volatility, and the product of the volatility of the domestic pricing kernel and exchange rate volatility:

$$
\frac{S_{i, j, t+\Delta}-F_{i, j, t, \Delta}}{S_{i, j, t}}=c_{0}+c_{1} \eta_{i} \sigma_{S}+c_{2} \sigma_{S}+\epsilon
$$


where $\Delta=1 / 12, i$ denotes the domestic currency while $j$ denotes the foreign currency, and the null is given by $H_{0}: c_{0}=0, c_{1} \neq 0$.

Although the unit-root null hypothesis is strongly rejected for spot exchange rate changes and the forward premium for all country pairs, ${ }^{29} \eta$ is highly persistent. Therefore, we estimate relation (28) using a cointegrating regression. The results for currency pairs and periods for which implied exchange rate volatility data are available are reported in Table 8.

The estimated coefficient of $\sigma_{S}$ is significant in nine out of the twelve regressions and that of the product term $\eta \sigma_{S}$ is significant in seven out of the twelve regressions. ${ }^{30}$ The estimated coefficient of the product of the pricing kernel and the exchange rate volatilities, $\hat{c}_{1}$, is significant in all the BPDM and USD-DM regressions, no matter whether the relevant independent variable is the estimated volatility of the pricing kernel for the USD, the BP, or the DM. On the other hand, $\hat{c}_{1}$ is significant for the CAD-USD and BP-USD regressions only when the independent variable is the estimated volatility of the USD pricing kernel. When the independent variable is the estimated volatility of the JY pricing kernel, $\hat{c}_{1}$ is significant in the DM-JY regression, but not in the JY-USD regression. Despite the short sample period and the fact that the exchange rate volatility enters both terms in the regression, these regressions provide clear evidence that exchange risk premia are related to time-variation in both exchange risk and the volatility of the pricing kernel. They also support the view that predictability in foreign exchange returns is due to time-variation in general risk premia, since the predictability is associated with a pricing kernel volatility estimate that is derived from the estimated time-variation in other (bond) market risk premia.

Since the implied exchange rate volatility is available for only a short period of time and for certain currency pairs, we also consider the alternative specification (18), which expresses the drift of the log of the spot exchange rate, as a function of the nominal interest rate differential and the volatilities of the pricing kernels associated with the two currencies without involving the exchange rate volatility. Again applying the covered interest rate parity relation $\ln F_{t, \Delta}-\ln S_{t} \approx\left(R-R^{*}\right) \Delta$,

\footnotetext{
${ }^{29}$ The forward premium in general does not have a high enough autocorrelation coefficient: the highest among all country pairs is only 0.82. Roll and Yan (2000) find non-stationarity in the forward premium for a different sample period.

${ }^{30}$ The significant coefficient for the exchange rate volatility is consistent with the finding of Brandt and Santa-Clara (2002) where the implied volatility derived from currency options also has a significant coefficient, but contradicts the results in Baillie and Bollerslev (1989, 1990) and Bekaert and Hodrick (1993) where the conditional exchange rate volatility estimated from a GARCH model has no or only weak association with the drift of exchange rate.
} 
the drift term of equation (18) implies that for a discrete time interval, $\Delta$ :

$$
\begin{aligned}
\mathrm{E}\left(\ln S_{t+\Delta}-\ln S_{t}\right) & =\left(\ln F_{t, \Delta}-\ln S_{t}\right) \\
& +\left[\left(\frac{1}{2} \sigma_{P}^{2}-\frac{1}{2} \sigma_{P^{*}}^{2}\right)+\frac{1}{2} \eta^{2}-\frac{1}{2}\left(\eta^{*}\right)^{2}+\sigma_{P} \rho_{P m} \eta-\sigma_{P^{*}} \rho_{P^{*} m^{*}} \eta^{*}\right] \Delta .
\end{aligned}
$$

Subtracting the log forward premium from both sides we obtain the following stochastic relation:

$$
\ln S_{i, j, t+\Delta}-\ln F_{i, j, t, \Delta}=c_{0}+c_{2} \eta_{i, t}^{2}+c_{3} \eta_{j, t}^{2}+c_{4} \eta_{i}+c_{5} \eta_{j}+\epsilon
$$

where $\Delta=1 / 12$, and $i$ denotes the domestic currency while $j$ denotes the foreign currency. For the true pricing kernel volatilities, $c_{2}=-c_{3}=\frac{1}{24}$ under the null. As mentioned above, the pricing kernel volatilities were empirically estimated only up to a scale factor so that $c_{2}$ and $-c_{3}$ are not constrained except as to sign. If unexpected inflation is priced so that $\rho_{P m} \neq 0$ and $\rho_{P^{*} m^{*}} \neq 0$, then the model predicts that $c_{4} \neq 0$ and $c_{5} \neq 0$.

The results of estimating equation (30) by cointegrating regression are reported in Table 9; for ease of presentation we report results for both definitions of the exchange rate, $\mathrm{S}$ and $1 / \mathrm{S}$. The strong association between pricing kernel volatilities and exchange rate risk premia remains in the new specification, and extends to the new currency pairs. At least one pricing kernel volatility is significantly associated with the foreign exchange risk premium for seven out of the ten currency pairs. However, the sign restrictions on $c_{2}$ and $c_{3}$ are frequently violated. We conjecture that this is due to the difficulty of identifying the separate coefficients of $\eta$ and $\eta^{2}$, and the errors in our estimates of these state variables.

In order to determine whether the time variation in risk premia that is captured by the estimated pricing kernel volatilities can account for the forward premium puzzle, we include the pricing kernel volatilities in a regression of the (log) change in spot rate on the log forward premium:

$$
\ln S_{i, j, t+\Delta}-\ln S_{i, j, t, \Delta}=c_{0}+c_{1}\left(\ln F_{t, \Delta}-\ln S_{t}\right)+c_{2} \eta_{i, t}^{2}+c_{3} \eta_{j, t}^{2}+c_{4} \eta_{i}+c_{5} \eta_{j}+\epsilon .
$$

Now $c_{1}$ estimated as a free parameter instead of being restricted to unity as in (30).

The cointegrating regression estimates are reported in Table 10. It is apparent that the estimates of $c_{1}$ are highly variable and often far (and significantly different) from their theoretical value of unity. However, while the precision weighted average of the coefficients for the simple regression on the forward premium reported in Table 7 was, including (excluding) the JY regression -0.40 $(-0.01)$, the precision weighted average of the estimates of $c_{1}$ in Table 10 is -0.20 (0.93). Thus, while the individual regressions in Table 10 show that the estimated pricing kernel volatilities do 
not account for the forward premium puzzle for particular exchange rates, their inclusion in the regression considerably attenuates the puzzle on average, and on average accounts for it almost entirely if the regressions involving the JY are excluded. A log likelihood ratio test rejects the null hypothesis that $c_{2}=c_{3}=c_{4}=c_{5}=0$ at better than $1 \%$ significance level in all cases, so that the pricing kernel volatility terms add significant explanatory power in all 20 regressions.

These results, taken together, support the view that foreign exchange risk is priced, and that the risk premia vary with both the overall level of risk premia for payoffs in a given currency, as measured by the volatility of the pricing kernel, and with the level of exchange rate volatility. While inclusion of the estimated pricing kernel volatilities does not eliminate the forward premium puzzle for particular exchange rates, it does on average attenuate it, and for the currencies where the proposed essentially affine term structure model seems appropriate on average almost eliminates it. Given the restrictive form of the term structure model, and the strong maintained assumptions that inflation volatility as well as all correlations with the pricing kernel are constant over time, the results offer strong support for a risk-premium based explanation of the forward premium puzzle.

\section{Conclusion}

In this paper, we have shown that there exists a simple relation between the volatilities of the pricing kernels (or maximum Sharpe ratios) for returns denominated in different currencies and the volatility of the exchange rate between them. We have also shown that the foreign exchange risk premium can be expressed in two alternative but equivalent forms. First as a sum of two terms: one that is proportional to the volatility of the domestic currency pricing kernel and the other that is proportional to the product of the volatility of the pricing kernel and the volatility of the exchange rate. Secondly, as a quadratic function of the volatilities of the pricing kernels of the two currencies.

The volatilities of the pricing kernels (Sharpe ratios) associated with five major currencies were estimated from (monthly) panel data on zero coupon bond yields and inflation using the parsimonious three-factor essentially affine term structure model proposed by Brennan, Wang and Xia (2003) which allows for time-variation in the volatility of the pricing kernel. The term structure model implies that bond yields are linear functions of the instantaneous real interest rate, the expected rate of inflation and the pricing kernel volatility, and the Kalman filter estimation yielded estimates of these three state variables for each currency/country.

The empirical relations between the estimated pricing kernel volatilities for different currencies were investigated by regressing first differences of one volatility on first differences of another and by 
co-integrating regressions that include an estimate of the exchange rate volatility. The co-integrating regressions reveal strong relations between the pricing kernel volatilities for different currencies and the exchange rate volatility: and the results of the first difference regressions are significantly stronger in the second half of the sample period, suggesting that capital market integration may have improved over time.

The negative correlation between the forward premium and the subsequent change in the spot exchange rate, the "forward premium puzzle" was manifest in the data for all currencies except the DM. However, as the first expression for the foreign exchange risk premium predicts, returns to foreign currency investment were found to be reliably related to time-variation in both the estimated volatility of the domestic pricing kernel and the exchange rate volatility. Data on exchange rate implied volatilities were available for only a limited set of currencies and dates. Therefore, the ability of the estimated volatilities of the foreign and domestic pricing kernels alone (without the exchange rate volatility) to capture time variation in the exchange rate risk premia was also evaluated. In general the estimated pricing kernel volatilities had significant explanatory power for the returns to foreign currency investment. However, the signs of the coefficients were not always as predicted, and when the forward premium was included as an independent variable it often entered with the wrong sign as in the forward premium puzzle regressions. Nevertheless, it was found that the sign of (precision-weighted) average coefficient of the forward premium changed from negative to positive when the pricing kernel volatilities were included; and when the JY, for which the pricing kernel volatility estimates were most problematic, was excluded, the average coefficient estimate of 0.93 is close to the theoretical value of unity.

These findings support the notion that risk premia in foreign exchange markets vary with the general level of risk premia in the corresponding bond markets and, given the restrictive nature of the essentially affine term structure model which was used to estimate the pricing kernel volatilities, the results are supportive of a rational explanation of the forward premium puzzle. However, further work is required to identify the volatility of the pricing kernels more precisely, and it would be desirable to allow for time variation in the correlations of state variable innovations with the pricing kernels which have been assumed constant throughout the paper. 


\section{References}

Backus, D., A. Gregory, and C. Telmer, 1993, Accounting for Forward Rates in Markets for Foreign Currency, The Journal of Finance 48, 1887-1908.

Backus, D., S. Foresi, and C. Telmer, 2001, Affine Term Structure Models and the Forward Premium Anomaly, Journal of Finance 56, 279-304.

Baillie, R., and T. Bollerslev, 1989, The Message in Daily Exchange Rates: A Conditional Variance Tale, Journal of Business and Economic Statistics 7, 297-305.

Baillie, R., and T. Bollerslev, 1990, A Multivariate Generalized GARCH Approach to Modeling Risk Premia in Foreign Exchange Markets, Journal of International Money and Finance 9, 309-324.

Bansal, R., 1997, An Exploration of the Forward Premium Puzzle in Currency Markets, Review of Financial Studies 10, 369-403.

Bansal, R., and M. Dahlquist, 2000, Journal of International Economics, 51, 115-144.

Bekaert, G., 1996, The Time-variation of Risk and Return in Foreign Exchange Markets: A General Equilibrium Perspective, Review of Financial Studies 9, 427-470.

Bekaert, G., and R. Hodrick, 1992, Characterizing Predictable Components in Excess Returns on Equity and Foreign Exchange Markets, The Journal of Finance 47, 467-509.

Bekaert, G., and R. Hodrick, 1993, On Biases in the Measurement of Foreign Exchange Risk Premiums, Journal of International Money and Finance 12, 115-138.

Bliss, R. R., 1996, Testing Term Structure Estimation Methods, Advances in Futures and Option Research 9, 197-231.

Brandt, M., and P. Santa-Clara, 2002, Simulated likelihood estimation of diffusions with an application to exchange rate dynamics in incomplete markets, Journal of Financial Economics 63, 161-210.

Brandt, M., J. Cochrane, and P. Santa-Clara, 2003, International risk sharing is better than you think (or exchange rates are much too smooth), unpublished manuscript, UCLA.

Brennan, M.J., and Y. Xia, 2003, Risk and Valuation under an Intertemporal Capital Asset Pricing Model, Working Paper, University of Pennsylvania.

Brennan, M.J., A. Wang, and Y. Xia, 2003, Estimation and Test a Simple Intertemporal Capital 
Asset Pricing Model, Working paper, University of Pennsylvania.

Chernov, M., 2002, On the Role of Volatility Risk Premia in Implied Volatilities Based Forecasting Regressions, working paper, Columbia University.

Dai, Q., and K. Singleton, 2003, Term Structure Dynamics in theory and Reality, Review of Financial Studies, 16, 631-678.

Domowitz, I., and C. Hakkio, 1985, Conditional Variance and the Risk Premium in the Foreign Exchange Market, Journal of International Economics 19, 47-66.

Duffee, G., 2002, Term Premia and Interest Rate Forecasts in Affine Models, Journal of Finance $57,405-443$.

Engel, C., 1996, The Forward Discount Anomaly and the Risk Premium: A Survey of Recent Evidence, Journal of Empirical Finance 3, 123-192.

Fama, E.F., 1984, Forward and Spot Exchange Rates, Journal of Monetary Economics 14, 319338.

Fama, E.F., and R.R. Bliss, 1987, the Information in Long Maturity Forward Rates, American Economic Review, 77, 680-692.

Fama, E.F., and K.R. French, 1987, Commodity Futures Prices: Some Evidence on Forecast Power, Premiums, and the theory of Storage, Journal of Business 60, 55-73.

Frankel J.A., and K.A. Froot, 1987, Using Survey Data to Test Standard Propositions Regarding Exchange Rate Expectations, American Economic Review,77, 133-153.

Hamilton, J., 1994, Time Series Analysis, (Princeton University Press, Princeton, New Jersey).

Huang, C-f., 1985, Information Structure and Equilibrium Asset Prices, Journal of Economic Theory 31, 33-71.

Ilmanen, A., 1995, Time-Varying Expected Returns in International Bond Markets, The Journal of Finance 50, 481-506.

Jorion, P., 1995, Predicting Volatility in the Foreign Exchange Market, The Journal of Finance $50,507-528$.

Korajczyk, R., and C. Viallet, 1990, An Empirical Investigation of International Asset Pricing, Review of Financial Studies 2, 53-85. 
Lewis, K., 1995, Puzzles in International Financial Markets, in G. M. Grossman and K. Rogeff eds Handbook of International Economics, Vol. 3, Chapter 13, Amsterdam, Elsevier.

Litzenberger, R.H., and J. Rolfo, 1984, An International Study of Tax Effects on Government Bonds Journal of Finance 39, 1-22.

Mehra, R., and E.C. Prescott, 1985, The Equity Premium: a Puzzle, Journal of Monetary Economics,15, 145-161.

McCulloch, J.H., 1975, The Tax Adjusted Yield Curves, The Journal of Finance 30, 811-830.

Neely, Christopher J., 2003, Forecasting Foreign Exchange Volatility: Is Implied Volatility the Best We Can Do?, working paper, Federal Reserve Bank of St. Louis.

Nielsen, Lars Tyge, and Jesús Saá-Requejo, 1993, Exchange Rate and term structure dynamics and the pricing of derivative securities, working paper, INSEAD.

Roll, R., and S. Yan, 2000, An Explanation of the Forward Premium "Puzzle", European Financial Management 6, 121-148.

Saá-Requejo, J., 1993, The dynamics and the term structure of risk premium in foreign exchange market, working paper, INSEAD. 
Table 1

Summary Statistics of Fitted Zero-Coupon Constant Maturity Bond Yields

This table reports summary statistics for fitted zero-coupon constant maturity bond yields. The bond yields are estimated from government coupon bonds using a cubic spline. The raw government coupon bond data are collected from Datastream. The sample is from January 1985 to May 2002

\begin{tabular}{|c|c|c|c|c|c|c|c|c|c|}
\hline \multirow[b]{3}{*}{ Securities } & \multicolumn{7}{|c|}{ 1. The United States } & \multirow{3}{*}{$\begin{array}{c}\text { CPI } \\
\text { Inflation }\end{array}$} & \multirow{3}{*}{$\begin{array}{l}\text { Excess } \\
\text { Mkt Ret }\end{array}$} \\
\hline & \multicolumn{7}{|c|}{ Bond Yield Maturities } & & \\
\hline & 0.5 & 1 & 2 & 3 & 5 & 7 & 10 & & \\
\hline Mean (\% per year) & 6.07 & 6.14 & 6.27 & 6.41 & 6.69 & 6.96 & 7.41 & 3.08 & 9.97 \\
\hline Std. Dev. (\% per year) & 1.64 & 1.59 & 1.58 & 1.61 & 1.53 & 1.19 & 0.82 & 0.77 & 15.04 \\
\hline Autocorrelation & 0.98 & 0.98 & 0.98 & 0.98 & 0.98 & 0.98 & 0.98 & 0.34 & 0.00 \\
\hline \multicolumn{10}{|l|}{ Correlation } \\
\hline 0.5 & 1.0 & 0.99 & 0.92 & 0.84 & 0.73 & 0.74 & 0.74 & 0.26 & -0.03 \\
\hline 1 & & 1.0 & 0.97 & 0.91 & 0.81 & 0.81 & 0.72 & 0.29 & -0.02 \\
\hline 2 & & & 1.0 & 0.98 & 0.93 & 0.88 & 0.67 & 0.27 & 0.01 \\
\hline 3 & & & & 1.0 & 0.98 & 0.92 & 0.62 & 0.26 & 0.03 \\
\hline 5 & & & & & 1.0 & 0.95 & 0.61 & 0.25 & 0.02 \\
\hline 7 & & & & & & 1.0 & 0.80 & 0.28 & -0.05 \\
\hline 10 & & & & & & & 1.0 & 0.29 & -0.17 \\
\hline \multirow{3}{*}{ Inflation } & & & & & & & & 1.0 & -0.09 \\
\hline & \multicolumn{7}{|c|}{ 2. Canada } & & \\
\hline & \multicolumn{7}{|c|}{ Bond Yield Maturities } & CPI & Excess \\
\hline Securities & 0.5 & 1 & 2 & 3 & 5 & 7 & 10 & Inflation & Mkt Ret. \\
\hline Mean (\% per year) & 6.99 & 7.09 & 7.18 & 7.45 & 7.70 & 7.84 & 8.01 & 2.78 & 5.50 \\
\hline Std. Dev. (\% per year) & 2.53 & 2.43 & 2.26 & 2.14 & 1.99 & 1.88 & 1.82 & 1.13 & 14.84 \\
\hline Autocorrelation & 0.98 & 0.98 & 0.98 & 0.98 & 0.98 & 0.98 & 0.98 & 0.09 & 0.09 \\
\hline \multicolumn{10}{|l|}{ Correlation } \\
\hline 0.5 & 1.0 & 0.998 & 0.98 & 0.96 & 0.89 & 0.87 & 0.87 & 0.32 & -0.16 \\
\hline 1 & & 1.0 & 0.99 & 0.97 & 0.91 & 0.90 & 0.89 & 0.32 & -0.16 \\
\hline 2 & & & 1.0 & 0.99 & 0.96 & 0.94 & 0.92 & 0.32 & -0.15 \\
\hline 3 & & & & 1.0 & 0.98 & 0.97 & 0.94 & 0.32 & -0.15 \\
\hline 5 & & & & & 1.0 & 0.99 & 0.96 & 0.30 & -0.13 \\
\hline 7 & & & & & & 1.0 & 0.99 & 0.28 & -0.12 \\
\hline 10 & & & & & & & 1.0 & 0.25 & -0.12 \\
\hline Inflation & & & & & & & & 1.0 & -0.01 \\
\hline
\end{tabular}


Table 1 (continued)

\begin{tabular}{|c|c|c|c|c|c|c|c|c|c|}
\hline \multirow[b]{3}{*}{ Securities } & \multicolumn{9}{|c|}{ 3. The United Kingdom (from Bank of England) } \\
\hline & \multicolumn{7}{|c|}{ Bond Yield Maturities } & \multirow{3}{*}{$\begin{array}{c}\text { CPI } \\
\text { Inflation } \\
3.80\end{array}$} & \multirow{3}{*}{$\begin{array}{l}\text { Excess } \\
\text { Mkt Ret }\end{array}$} \\
\hline & 1 & 2 & 3 & 5 & 7 & 10 & 15 & & \\
\hline Mean (\% per year) & 8.02 & 8.03 & 8.06 & 8.11 & 8.14 & 8.10 & 7.88 & & \\
\hline Std. Dev. (\% per year) & 2.65 & 2.35 & 2.21 & 2.13 & 2.12 & 2.10 & 1.97 & 1.63 & 16.73 \\
\hline Autocorrelation & 0.99 & 0.98 & 0.98 & 0.98 & 0.98 & 0.99 & 0.99 & 0.24 & 0.03 \\
\hline \multicolumn{10}{|l|}{ Correlation } \\
\hline 1 & 1.0 & 0.99 & 0.97 & 0.93 & 0.90 & 0.87 & 0.80 & 0.36 & -0.03 \\
\hline 2 & & 1.0 & 0.99 & 0.97 & 0.95 & 0.92 & 0.86 & 0.36 & -0.04 \\
\hline 3 & & & 1.0 & 0.99 & 0.98 & 0.95 & 0.90 & 0.35 & -0.04 \\
\hline 5 & & & & 1.0 & 0.99 & 0.98 & 0.95 & 0.34 & -0.03 \\
\hline 7 & & & & & 1.0 & 0.99 & 0.97 & 0.32 & -0.03 \\
\hline 10 & & & & & & 1.0 & 0.99 & 0.30 & -0.01 \\
\hline 15 & & & & & & & 1.0 & 0.27 & 0.01 \\
\hline \multirow[t]{3}{*}{ Inflation } & & & & & & & & 1.0 & -0.09 \\
\hline & \multicolumn{7}{|c|}{ 4. Germany } & & \\
\hline & \multicolumn{7}{|c|}{ Bond Yield Maturities } & CPI & Excess \\
\hline Securities & 0.5 & 1 & 2 & 3 & 5 & 7 & & Inflation & Mkt Ret. \\
\hline Mean (\% per year) & 5.25 & 5.59 & 5.69 & 5.67 & 5.84 & 6.17 & & 1.96 & 7.45 \\
\hline Std. Dev. (\% per year) & 1.90 & 1.64 & 1.50 & 1.45 & 1.38 & 1.24 & & 0.91 & 19.87 \\
\hline Autocorrelation & 0.97 & 0.98 & 0.98 & 0.99 & 0.99 & 0.98 & & 0.26 & 0.07 \\
\hline \multicolumn{10}{|l|}{ Correlation } \\
\hline 0.5 & 1.0 & 0.92 & 0.85 & 0.81 & 0.69 & 0.63 & & 0.25 & -0.06 \\
\hline 1 & & 1.0 & 0.97 & 0.88 & 0.71 & 0.66 & & 0.25 & -0.07 \\
\hline 2 & & & 1.0 & 0.96 & 0.83 & 0.78 & & 0.26 & -0.07 \\
\hline 3 & & & & 1.0 & 0.95 & 0.90 & & 0.26 & -0.07 \\
\hline 5 & & & & & 1.0 & 0.98 & & 0.24 & -0.07 \\
\hline 7 & & & & & & 1.0 & & 0.22 & -0.08 \\
\hline \multirow[t]{3}{*}{ Inflation } & & & & & & & & 1.0 & -0.04 \\
\hline & \multicolumn{7}{|c|}{ 5. Japan } & & \\
\hline & \multicolumn{7}{|c|}{ Bond Yield Maturities } & CPI & Excess \\
\hline Securities & 0.5 & 1 & 2 & 3 & 5 & 8 & & Inflation & Mkt Ret. \\
\hline Mean (\% per year) & 2.98 & 2.92 & 2.95 & 3.12 & 3.52 & 3.92 & & 0.84 & 1.67 \\
\hline Std. Dev. (\% per year) & 2.37 & 2.36 & 2.32 & 2.23 & 2.05 & 1.89 & & 1.46 & 20.31 \\
\hline Autocorrelation & 0.99 & 0.99 & 0.99 & 0.99 & 0.99 & 0.99 & & 0.18 & 0.10 \\
\hline \multicolumn{10}{|l|}{ Correlation } \\
\hline 0.5 & 1.0 & 0.99 & 0.99 & 0.98 & 0.97 & 0.96 & & 0.20 & -0.05 \\
\hline 1 & & 1.0 & 0.99 & 0.99 & 0.98 & 0.96 & & 0.20 & -0.05 \\
\hline 2 & & & 1.0 & 0.99 & 0.98 & 0.97 & & 0.19 & -0.05 \\
\hline 3 & & & & 1.0 & 0.99 & 0.98 & & 0.20 & -0.05 \\
\hline 5 & & & & & 1.0 & 0.99 & & 0.19 & -0.05 \\
\hline 8 & & & & & & 1.0 & & 0.18 & -0.04 \\
\hline Inflation & & & & & & & & 1.0 & -0.00 \\
\hline
\end{tabular}


Table 2

Summary Statistics For Foreign Exchange Rates, Foreign Exchange Volatilities and Interest Rates

This table reports summary statistics for changes in spot exchange rates, $S_{t+1} / S_{t}-1$, one-month treasury bill rates, $R$, and one-month forward premia, $\ln F_{t}-\ln S_{t} . F_{t}$ and $S_{t}$ are measured as dollars per unit of foreign currency. The sample is from January 1985 to May 2002 for BP, CAD and JY, and the sample ends in December 1998 for the DM due to the introduction of the Euro. The DM treasury bill rates are from Bloomberg and the JY treasury bill rates are imputed from other treasury yields. All other data except for implied volatilities are as of the beginning of the month and are from Datastream. The implied volatility of exchange rates are for foreign currencies per U.S. dollar. The data are measured at the end of the month from October 1994 to May 2002 and are from the Federal Reserve Bank of New York.

\begin{tabular}{|c|c|c|c|}
\hline Currency & Mean & Std Deviation & Autocorrelation \\
\hline \multicolumn{4}{|c|}{$\begin{array}{l}\text { 1. Change in the Spot Rate: } S_{t+1} / S_{t}-1 \\
\text { (\% per month) }\end{array}$} \\
\hline British Pound & 0.17 & 3.09 & 0.052 \\
\hline Canadian Dollar & -0.07 & 1.37 & -0.063 \\
\hline German Mark & 0.44 & 3.43 & -0.011 \\
\hline Japanese Yen & 0.39 & 3.74 & 0.030 \\
\hline \multicolumn{4}{|c|}{$\begin{array}{l}\text { 2. Forward Premium: } 100 \times\left(\ln F_{t}-\ln S_{t}\right) \\
(\% \text { per month })\end{array}$} \\
\hline British Pound & -0.23 & 0.21 & 0.744 \\
\hline Canadian Dollar & -0.09 & 0.21 & 0.470 \\
\hline German Mark & 0.04 & 0.29 & 0.746 \\
\hline Japanese Yen & 0.24 & 0.26 & 0.494 \\
\hline \multicolumn{4}{|c|}{$\begin{array}{l}\text { 3. One-month Treasury Bill Rates } \\
\text { (\% per year) }\end{array}$} \\
\hline U.S. Dollar & 5.27 & 1.55 & 0.886 \\
\hline British Pound & 8.34 & 3.16 & 0.985 \\
\hline Canadian Dollar & 6.78 & 2.96 & 0.977 \\
\hline German Mark & 5.19 & 1.91 & 0.989 \\
\hline Japanese Yen & 2.99 & 2.69 & 0.995 \\
\hline \multicolumn{4}{|c|}{$\begin{array}{l}\text { 4. One-month Implied Volatility of Exchange Rates: } \\
\text { (\% per year) }\end{array}$} \\
\hline British Pound & 8.32 & 1.54 & 0.603 \\
\hline Canadian Dollar & 5.82 & 1.60 & 0.824 \\
\hline German Mark & 10.64 & 2.21 & 0.718 \\
\hline Japanese Yen & 12.02 & 3.15 & 0.716 \\
\hline
\end{tabular}


Table 3

\section{Summary Statistics For Foreign Exchange Cross-Rates}

This table reports summary statistics for changes in spot exchange rates, $S_{t+1} / S_{t}-1$, and one-month forward premia, $\ln F_{t}-\ln S_{t}$ for cross exchange rates calculated from beginning of month USD rates taken from Datastream. Implied volatilities for the BP/DM and DM/JY rates are from the Federal Reserve Bank of New York for the period from October 1994 to May 2002.

\begin{tabular}{lccc}
\hline Currency & Mean & Std Deviation & Autocorrelation \\
\hline 1. Change in the Spot Rate: $S_{t+1} / S_{t}-1$ & & & \\
(\% per month) & & & \\
Canadian Dollar/German Mark & 0.33 & 3.56 & 0.010 \\
Canadian Dollar/Japanese Yen & 0.48 & 3.90 & 0.014 \\
Canadian Dollar/British Pound & 0.25 & 3.17 & -0.007 \\
Canadian Dollar/U.S. Dollar & 0.09 & 1.38 & -0.061 \\
German Mark/Japanese Yen & 0.20 & 3.37 & 0.015 \\
German Mark/British Pound & -0.04 & 2.48 & 0.109 \\
German Mark/U.S. Dollar & -0.13 & 3.36 & 0.014 \\
Japanese Yen/British Pound & -0.14 & 3.60 & 0.053 \\
Japanese Yen/U.S. Dollar & -0.26 & 3.63 & 0.031 \\
British Pound/U.S. Dollar & -0.07 & 3.13 & -0.070 \\
& & & \\
2. Forward Premium: 100 × (ln Ft $\left.-\ln S_{t}\right)$ & & & \\
(\% per month) & & & \\
Canadian Dollar/German Mark & 0.16 & 0.28 & 0.629 \\
Canadian Dollar/Japanese Yen & 0.33 & 0.26 & 0.092 \\
Canadian Dollar/British Pound & -0.14 & 0.21 & 0.139 \\
Canadian Dollar/U.S. Dollar & 0.09 & 0.21 & 0.470 \\
German Mark/Japanese Yen & 0.17 & 0.22 & 0.496 \\
German Mark/British Pound & -0.31 & 0.26 & 0.821 \\
German Mark/U.S. Dollar & -0.04 & 0.29 & 0.746 \\
Japanese Yen/British Pound & -0.47 & 0.22 & 0.322 \\
Japanese Yen/U.S. Dollar & -0.24 & 0.26 & 0.494 \\
British Pound/U.S. Dollar & 0.23 & 0.21 & 0.744 \\
4. & & & \\
One-month Implied Volatility of Exchange Rates: & & & \\
British Pound/German Mark & & & \\
German Mark/Japanese Yen & 8.48 & 2.02 & 0.835 \\
\hline
\end{tabular}


Table 4

\section{Term Structure Model Parameter Estimates}

This table reports estimates of the parameters of the stochastic process of the investment opportunity set, equations (22) to (24), obtained from a Kalman filter applied to inflation rates and bond yields. The state variables are $r$, the real interest rate, $\pi$, the expected rate of inflation, and $\eta$, the volatility of the pricing kernel or the Sharpe ratio of the economy. In the table, $m$ denotes the pricing kernel and $P$ is the price level. Asymptotic t-ratios are in parentheses.

\begin{tabular}{|c|c|c|c|c|c|c|c|}
\hline \multicolumn{8}{|c|}{ 1. The United States } \\
\hline $\begin{array}{l}\text { Estimate } \\
\text { t-ratio }\end{array}$ & $\begin{array}{c}\sigma_{b} \\
0.48 \% \\
(52.82)\end{array}$ & $\begin{array}{c}\sigma_{r} \\
2.77 \% \\
(10.92)\end{array}$ & $\begin{array}{c}\sigma_{\pi} \\
0.81 \% \\
(5.15)\end{array}$ & $\begin{array}{c}\sigma_{\eta} \\
0.193 \\
(1.88)\end{array}$ & $\begin{array}{c}\kappa_{r} \\
0.290 \\
(1.97)\end{array}$ & $\begin{array}{c}\kappa_{\pi} \\
0.002 \\
(0.70)\end{array}$ & $\begin{array}{c}\kappa_{\eta} \\
0.292 \\
(3.84)\end{array}$ \\
\hline $\begin{array}{l}\text { Estimate } \\
\text { t-ratio }\end{array}$ & $\begin{array}{c}\rho_{r \pi} \\
0.027 \\
(0.11)\end{array}$ & $\begin{array}{c}\rho_{r \eta} \\
-0.413 \\
(0.54)\end{array}$ & $\begin{array}{c}\rho_{r m} \\
-0.801 \\
(6.22)\end{array}$ & $\begin{array}{c}\rho_{\pi \eta} \\
-0.199 \\
(0.69)\end{array}$ & $\begin{array}{c}\rho_{\pi m} \\
-0.276 \\
(1.66)\end{array}$ & $\begin{array}{c}\rho_{\eta m} \\
0.919 \\
(2.57)\end{array}$ & \\
\hline Pre-set Value & $\begin{array}{c}\bar{r} \\
2.62 \%\end{array}$ & $\begin{array}{c}\bar{\pi} \\
3.00 \%\end{array}$ & $\begin{array}{c}\bar{\eta} \\
0.62\end{array}$ & $\begin{array}{c}\sigma_{P} \\
0.77 \%\end{array}$ & $\begin{array}{c}\rho_{P m} \\
0.00\end{array}$ & $\begin{array}{c}M L \\
9,334.6\end{array}$ & \\
\hline \multicolumn{8}{|c|}{ 2. Canada } \\
\hline $\begin{array}{l}\text { Estimate } \\
\text { t-ratio }\end{array}$ & $\begin{array}{c}\sigma_{b} \\
0.38 \% \\
(50.65)\end{array}$ & $\begin{array}{c}\sigma_{r} \\
0.78 \% \\
(6.77)\end{array}$ & $\begin{array}{c}\sigma_{\pi} \\
0.74 \% \\
(4.64)\end{array}$ & $\begin{array}{c}\sigma_{\eta} \\
0.196 \\
(1.48)\end{array}$ & $\begin{array}{c}\kappa_{r} \\
0.119 \\
(3.35)\end{array}$ & $\begin{array}{c}\kappa_{\pi} \\
0.000 \\
(0.68)\end{array}$ & $\begin{array}{c}\kappa_{\eta} \\
0.073 \\
(2.44)\end{array}$ \\
\hline $\begin{array}{l}\text { Estimate } \\
\text { t-ratio }\end{array}$ & $\begin{array}{c}\rho_{r \pi} \\
-0.080 \\
(0.37)\end{array}$ & $\begin{array}{c}\rho_{r \eta} \\
-0.181 \\
(0.70)\end{array}$ & $\begin{array}{c}\rho_{r m} \\
-0.865 \\
(2.51)\end{array}$ & $\begin{array}{c}\rho_{\pi \eta} \\
-0.254 \\
(0.91)\end{array}$ & $\begin{array}{c}\rho_{\pi m} \\
0.122 \\
(1.23)\end{array}$ & $\begin{array}{c}\rho_{\eta m} \\
0.915 \\
(2.09)\end{array}$ & \\
\hline Pre-set Value & $\begin{array}{c}\bar{r} \\
4.00 \%\end{array}$ & $\begin{array}{c}\bar{\pi} \\
2.78 \%\end{array}$ & $\begin{array}{c}\bar{\eta} \\
0.44\end{array}$ & $\begin{array}{c}\sigma_{P} \\
1.33 \%\end{array}$ & $\begin{array}{c}\rho_{P m} \\
0.00\end{array}$ & $\begin{array}{c}M L \\
8,561.5\end{array}$ & \\
\hline
\end{tabular}


Table 4 (continued)

\begin{tabular}{|c|c|c|c|c|c|c|c|}
\hline \multicolumn{8}{|c|}{ 3. The United Kingdom } \\
\hline $\begin{array}{l}\text { Estimate } \\
\text { t-ratio }\end{array}$ & $\begin{array}{c}\sigma_{b} \\
0.44 \% \\
(49.74)\end{array}$ & $\begin{array}{c}\sigma_{r} \\
0.63 \% \\
(10.35)\end{array}$ & $\begin{array}{c}\sigma_{\pi} \\
0.92 \% \\
(12.94)\end{array}$ & $\begin{array}{c}\sigma_{\eta} \\
0.207 \\
(2.45)\end{array}$ & $\begin{array}{c}\kappa_{r} \\
0.143 \\
(4.68)\end{array}$ & $\begin{array}{c}\kappa_{\pi} \\
0.000 \\
(0.76)\end{array}$ & $\begin{array}{c}\kappa_{\eta} \\
0.104 \\
(1.89)\end{array}$ \\
\hline $\begin{array}{l}\text { Estimate } \\
\text { t-ratio }\end{array}$ & $\begin{array}{c}\rho_{r \pi} \\
-0.104 \\
(0.75)\end{array}$ & $\begin{array}{c}\rho_{r \eta} \\
-0.234 \\
(1.14)\end{array}$ & $\begin{array}{c}\rho_{r m} \\
-0.714 \\
(3.49)\end{array}$ & $\begin{array}{c}\rho_{\pi \eta} \\
-0.191 \\
(0.78)\end{array}$ & $\begin{array}{c}\rho_{\pi m} \\
0.178 \\
(1.93)\end{array}$ & $\begin{array}{c}\rho_{\eta m} \\
0.833 \\
(4.38)\end{array}$ & \\
\hline Pre-set Value & $\begin{array}{c}\bar{r} \\
4.56 \%\end{array}$ & $\begin{array}{c}\bar{\pi} \\
3.78 \%\end{array}$ & $\begin{array}{c}\bar{\eta} \\
0.58\end{array}$ & $\begin{array}{c}\sigma_{P} \\
1.63 \%\end{array}$ & $\begin{array}{c}\rho_{P m} \\
0.00\end{array}$ & $\begin{array}{c}M L \\
8,522.2\end{array}$ & \\
\hline \multicolumn{8}{|c|}{ 4. Germany } \\
\hline $\begin{array}{l}\text { Estimate } \\
\text { t-ratio }\end{array}$ & $\begin{array}{c}\sigma_{b} \\
0.34 \% \\
(44.14)\end{array}$ & $\begin{array}{c}\sigma_{r} \\
0.83 \% \\
(5.93)\end{array}$ & $\begin{array}{c}\sigma_{\pi} \\
1.15 \% \\
(4.91)\end{array}$ & $\begin{array}{c}\sigma_{\eta} \\
0.281 \\
(0.75)\end{array}$ & $\begin{array}{c}\kappa_{r} \\
0.067 \\
(1.17)\end{array}$ & $\begin{array}{c}\kappa_{\pi} \\
0.799 \\
(4.44)\end{array}$ & $\begin{array}{c}\kappa_{\eta} \\
0.002 \\
(0.68)\end{array}$ \\
\hline $\begin{array}{l}\text { Estimate } \\
\text { t-ratio }\end{array}$ & $\begin{array}{c}\rho_{r \pi} \\
-0.101 \\
(0.33)\end{array}$ & $\begin{array}{c}\rho_{r \eta} \\
-0.217 \\
(0.65)\end{array}$ & $\begin{array}{c}\rho_{r m} \\
-0.984 \\
(3.41)\end{array}$ & $\begin{array}{c}\rho_{\pi \eta} \\
-0.142 \\
(0.54)\end{array}$ & $\begin{array}{c}\rho_{\pi m} \\
0.257 \\
(0.51)\end{array}$ & $\begin{array}{c}\rho_{\eta m} \\
0.939 \\
(2.12)\end{array}$ & \\
\hline Pre-set Value & $\begin{array}{c}\bar{r} \\
3.02 \%\end{array}$ & $\begin{array}{c}\bar{\pi} \\
2.45 \%\end{array}$ & $\begin{array}{c}\bar{\eta} \\
0.46\end{array}$ & $\begin{array}{c}\sigma_{P} \\
0.98 \%\end{array}$ & $\begin{array}{c}\rho_{P m} \\
0.00\end{array}$ & $\begin{array}{c}M L \\
7,405.9\end{array}$ & \\
\hline \multicolumn{8}{|c|}{ 5. Japan } \\
\hline $\begin{array}{l}\text { Estimate } \\
\text { t-ratio }\end{array}$ & $\begin{array}{c}\sigma_{b} \\
0.18 \% \\
(44.78)\end{array}$ & $\begin{array}{c}\sigma_{r} \\
0.92 \% \\
(4.52)\end{array}$ & $\begin{array}{c}\sigma_{\pi} \\
0.40 \% \\
(1.42)\end{array}$ & $\begin{array}{c}\sigma_{\eta} \\
0.065 \\
(1.76)\end{array}$ & $\begin{array}{c}\kappa_{r} \\
0.001 \\
(0.75)\end{array}$ & $\begin{array}{c}\kappa_{\pi} \\
0.119 \\
(1.86)\end{array}$ & $\begin{array}{c}\kappa_{\eta} \\
0.048 \\
(1.35)\end{array}$ \\
\hline $\begin{array}{l}\text { Estimate } \\
\text { t-ratio }\end{array}$ & $\begin{array}{c}\rho_{r \pi} \\
-0.154 \\
(0.27)\end{array}$ & $\begin{array}{c}\rho_{r \eta} \\
-0.259 \\
(1.05)\end{array}$ & $\begin{array}{c}\rho_{r m} \\
-0.979 \\
(9.16)\end{array}$ & $\begin{array}{c}\rho_{\pi \eta} \\
-0.237 \\
(0.42)\end{array}$ & $\begin{array}{c}\rho_{\pi m} \\
0.343 \\
(0.39)\end{array}$ & $\begin{array}{c}\rho_{\eta m} \\
-0.146 \\
(0.23)\end{array}$ & \\
\hline Pre-set Value & $\begin{array}{c}\bar{r} \\
2.54 \%\end{array}$ & $\begin{array}{c}\bar{\pi} \\
1.14 \%\end{array}$ & $\begin{array}{c}\bar{\eta} \\
0.21\end{array}$ & $\begin{array}{c}\sigma_{P} \\
1.62 \%\end{array}$ & $\begin{array}{c}\rho_{P m} \\
0.00\end{array}$ & $\begin{array}{c}M L \\
7,969.4\end{array}$ & \\
\hline
\end{tabular}


Table 5

\section{Summary Statistics For Estimated State Variables}

This table reports summary statistics for the state variables $r, \pi$ and $\eta$, estimated from government bonds in the five countries. A cubic spline was used to estimate zero-coupon yields for maturities of $0.5,1,2,3,5,7$, and 10 years from bond prices taken from Datastream. The state variables were estimated from these yields using the Kalman filter algorithm. The sample is from January 1985 to May 2002. All data are as of the beginning of the month and are in annual terms.

\begin{tabular}{lccc}
\hline Currency & Mean & Standard Deviation & Autocorrelation \\
\hline 1. Instantaneous real risk free rate: $r$ & & & \\
U.S. Dollar & $3.21 \%$ & $1.70 \%$ & 0.964 \\
Canadian Dollar & $3.15 \%$ & $2.72 \%$ & 0.992 \\
British Pound & $4.34 \%$ & $2.40 \%$ & 0.989 \\
German Mark & $2.91 \%$ & $1.54 \%$ & 0.987 \\
Japanese Yen & $1.12 \%$ & $2.40 \%$ & 0.986 \\
2. Expected Inflation: $\pi$ & & & \\
U.S. Dollar & & & \\
Canadian Dollar & $2.79 \%$ & $0.71 \%$ & 0.970 \\
British Pound & $3.69 \%$ & $1.94 \%$ & 0.986 \\
German Mark & $3.52 \%$ & $2.10 \%$ & 0.984 \\
Japanese Yen & $2.34 \%$ & $0.96 \%$ & 0.974 \\
& $1.70 \%$ & $0.46 \%$ & \\
3. Maximum Sharpe Ratio: $\eta$ & & & 0.989 \\
U.S. Dollar & & & 0.995 \\
Canadian Dollar & 0.145 & 0.450 & 0.992 \\
British Pound & 0.754 & 0.940 & 0.994 \\
German Mark & 0.686 & 0.711 & 0.995 \\
Japanese Yen & 0.468 & 0.803 & \\
& 0.306 & 0.186 & \\
\hline
\end{tabular}




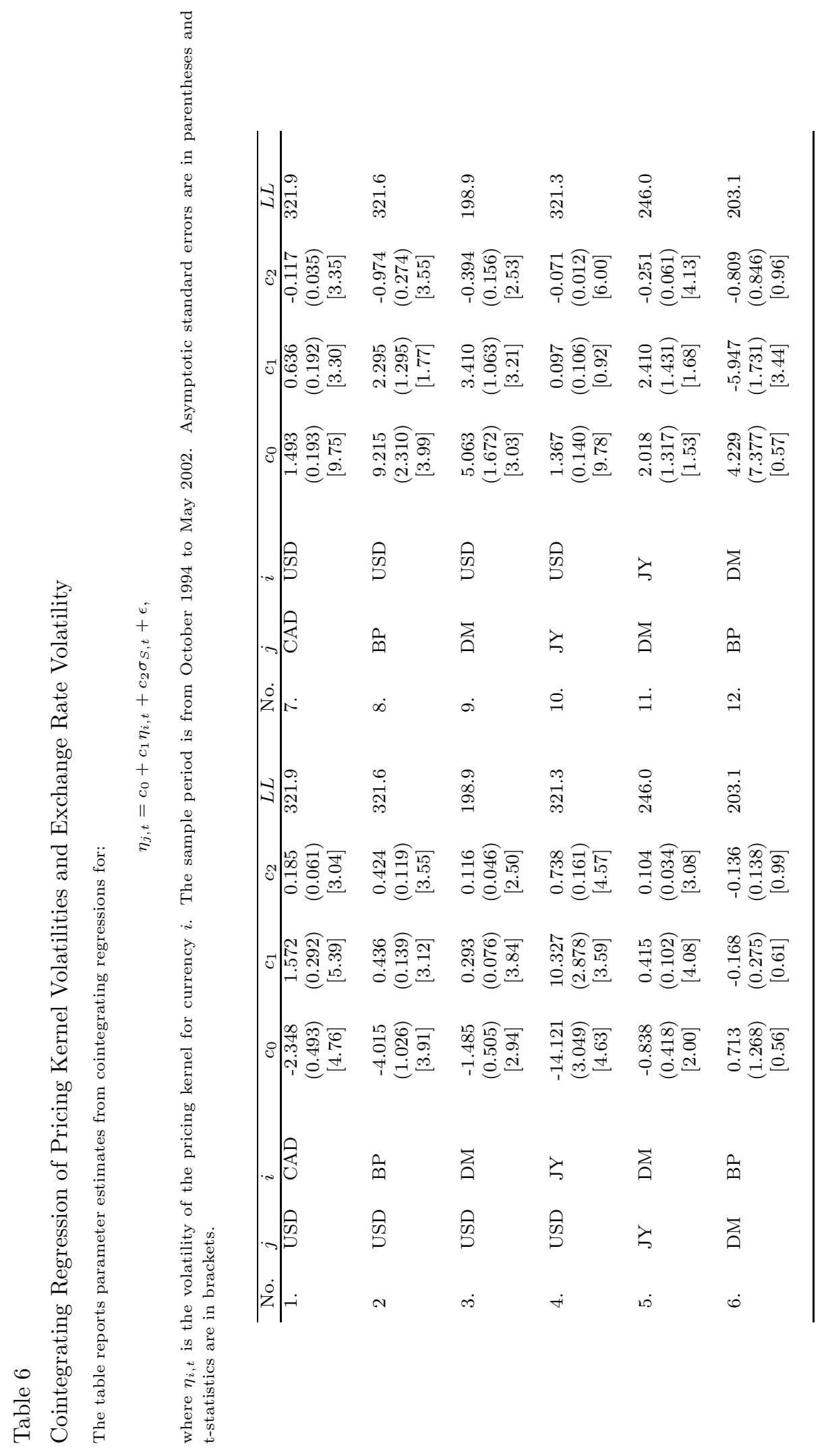


Table 7

Cointegrating Regression of log Spot Rate Change on log Forward Premium

The table reports parameter estimates from cointegrating regression estimates of:

$$
\ln S_{i, j, t+1}-\ln S_{i, j, t}=c_{0}+c_{1}\left(\ln F_{i, j, t, \Delta}-\ln S_{i, j, t}\right)
$$

where $S_{i, j, t}$ and $F_{i, j, t, \Delta}$ denote the spot and $\Delta$-period (one month) forward exchange rates between currencies $i$ and $j$ at time $t$ measured in units of currency $i$ per unit of currency $j$. Asymptotic standard errors are in parentheses and t-statistics are in brackets. The log likelihood function value $(L L)$ is calculated by using small sample degrees of freedom correction.

\begin{tabular}{|c|c|c|c|c|c|c|c|c|c|c|c|}
\hline No. & $i$ & $j$ & $c_{0}$ & $c_{1}$ & $L L$ & No. & $i$ & $j$ & $c_{0}$ & $c_{1}$ & $L L$ \\
\hline 1. & USD & CAD & $\begin{array}{r}-0.001 \\
(0.00) \\
{[1.01]}\end{array}$ & $\begin{array}{c}-0.302 \\
(0.50) \\
{[0.61]}\end{array}$ & 1609.3 & 13. & $\mathrm{DM}$ & CAD & $\begin{array}{c}-0.003 \\
(0.00) \\
{[0.84]}\end{array}$ & $\begin{array}{l}0.789 \\
(1.28) \\
{[0.62]}\end{array}$ & 1111.0 \\
\hline 2. & USD & DM & $\begin{array}{l}0.003 \\
(0.00) \\
{[1.12]}\end{array}$ & $\begin{array}{l}0.739 \\
(1.12) \\
{[0.66]}\end{array}$ & 1152.7 & 14. & $\mathrm{DM}$ & JY & $\begin{array}{c}0.000 \\
(0.00) \\
{[0.1]}\end{array}$ & $\begin{array}{l}0.961 \\
(1.59) \\
{[0.61]}\end{array}$ & 1137.4 \\
\hline 3. & USD & JY & $\begin{array}{l}0.009 \\
(0.00) \\
{[2.46]}\end{array}$ & $\begin{array}{r}-2.597 \\
(1.19) \\
{[2.18]}\end{array}$ & 1355.7 & 15. & $\mathrm{DM}$ & $\mathrm{BP}$ & $\begin{array}{l}0.000 \\
(0.00) \\
{[0.03]}\end{array}$ & $\begin{array}{l}0.586 \\
(1.09) \\
{[0.54]}\end{array}$ & 1255.0 \\
\hline 4. & USD & $\mathrm{BP}$ & $\begin{array}{l}0.000 \\
(0.00) \\
{[0.10]}\end{array}$ & $\begin{array}{c}-0.453 \\
(1.05) \\
{[0.43]}\end{array}$ & 1504.6 & 16. & DM & USD & $\begin{array}{c}-0.003 \\
(0.00) \\
{[1.12]}\end{array}$ & $\begin{array}{l}0.739 \\
(1.12) \\
{[0.66]}\end{array}$ & 1152.7 \\
\hline 5. & $\mathrm{BP}$ & CAD & $\begin{array}{c}-0.001 \\
(0.00) \\
{[0.31]}\end{array}$ & $\begin{array}{c}-0.196 \\
(1.92) \\
{[0.10]}\end{array}$ & 1394.1 & 17. & CAD & DM & $\begin{array}{l}0.003 \\
(0.00) \\
{[0.84]}\end{array}$ & $\begin{array}{l}0.789 \\
(1.28) \\
{[0.62]}\end{array}$ & 1111.0 \\
\hline 6. & $\mathrm{BP}$ & DM & $\begin{array}{l}0.000 \\
(0.00) \\
{[0.03]}\end{array}$ & $\begin{array}{l}0.586 \\
(1.09) \\
{[0.54]}\end{array}$ & 1255.0 & 18. & CAD & JY & $\begin{array}{c}0.018 \\
(0.01) \\
{[2.7]}\end{array}$ & $\begin{array}{c}-4.194 \\
(1.80) \\
{[2.33]}\end{array}$ & 1306.0 \\
\hline 7. & $\mathrm{BP}$ & JY & $\begin{array}{l}0.016 \\
(0.01) \\
{[1.72]}\end{array}$ & $\begin{array}{c}-2.908 \\
(1.87) \\
{[1.56]}\end{array}$ & 1361.5 & 19. & CAD & $\mathrm{BP}$ & $\begin{array}{l}0.001 \\
(0.00) \\
{[0.31]}\end{array}$ & $\begin{array}{c}-0.196 \\
(1.92) \\
{[0.10]}\end{array}$ & 1394.1 \\
\hline 8. & $\mathrm{BP}$ & USD & $\begin{array}{l}0.000 \\
(0.00) \\
{[0.10]}\end{array}$ & $\begin{array}{c}-0.453 \\
(1.05) \\
{[0.43]}\end{array}$ & 1504.6 & 20. & CAD & USD & $\begin{array}{l}0.001 \\
(0.00) \\
{[1.01]}\end{array}$ & $\begin{array}{c}-0.302 \\
(0.50) \\
{[0.61]}\end{array}$ & 1609.3 \\
\hline 9. & JY & CAD & $\begin{array}{c}-0.018 \\
(0.01) \\
{[2.70]}\end{array}$ & $\begin{array}{c}-4.194 \\
(1.80) \\
{[2.33]}\end{array}$ & 1306.0 & & & & & & \\
\hline 10. & JY & DM & $\begin{array}{l}0.000 \\
(0.00) \\
{[0.10]}\end{array}$ & $\begin{array}{l}0.961 \\
(1.59) \\
{[0.61]}\end{array}$ & 1137.4 & & & & & & \\
\hline 11. & JY & $\mathrm{BP}$ & $\begin{array}{c}-0.016 \\
(0.01) \\
{[1.72]}\end{array}$ & $\begin{array}{c}-2.908 \\
(1.87) \\
{[1.56]}\end{array}$ & 1361.5 & & & & & & \\
\hline 12. & JY & USD & $\begin{array}{c}-0.009 \\
(0.00) \\
{[2.46]}\end{array}$ & $\begin{array}{r}-2.597 \\
(1.19) \\
{[2.18]}\end{array}$ & 1355.7 & & & & & & \\
\hline
\end{tabular}




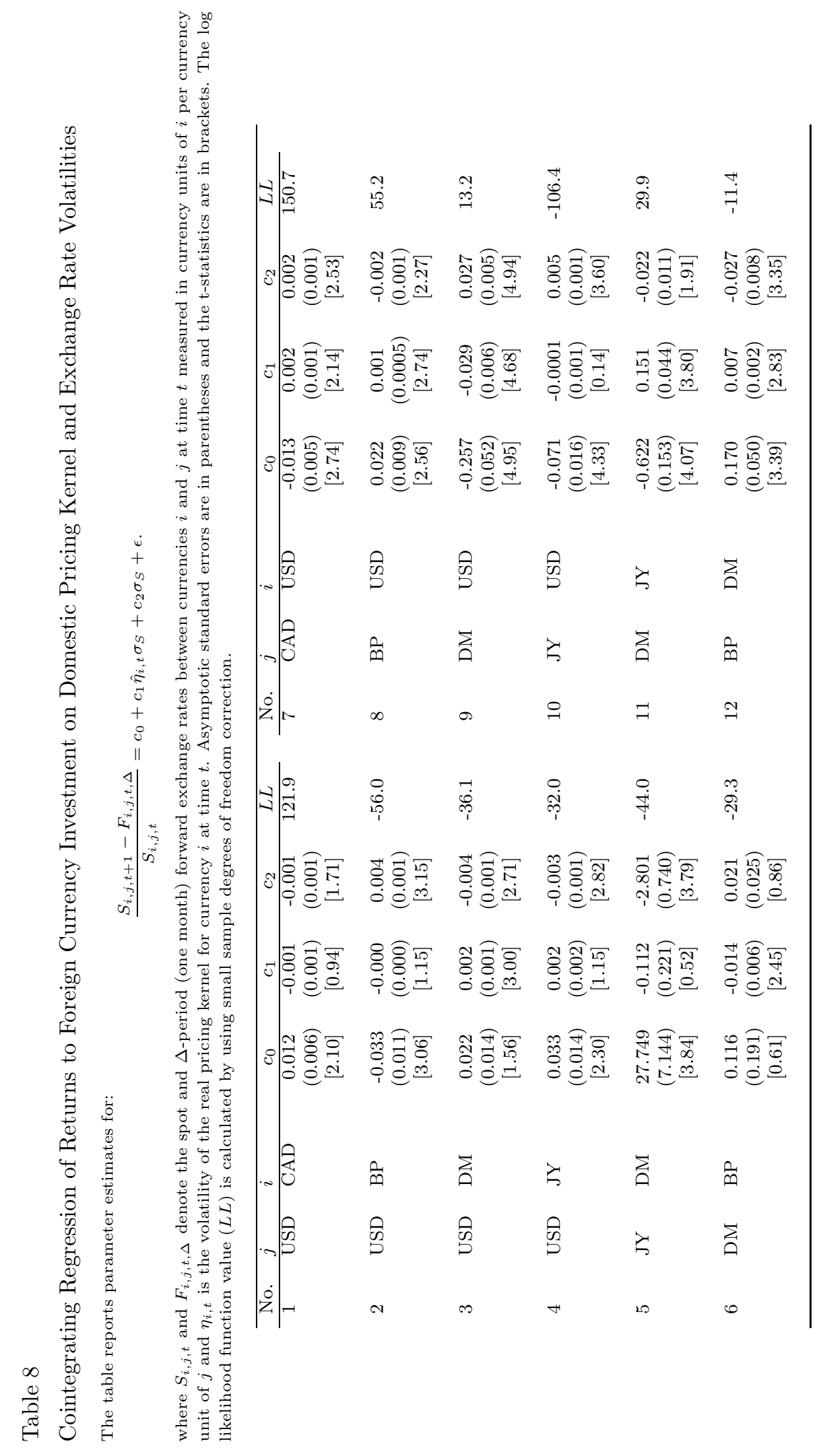


Table 9

Cointegrating Regression of log Return on Foreign Currency Investment on Domestic and Foreign Pricing Kernel Volatilities

The table reports parameter estimates for:

$$
\ln S_{i, j, t+\Delta}-\ln F_{i, j, t, \Delta}=c_{0}+c_{2} \hat{\eta}_{i, t}^{2}+c_{3} \hat{\eta}_{j, t}^{2}+c_{4} \hat{\eta}_{i, t}+c_{5} \hat{\eta}_{j, t}+\epsilon
$$

where $S_{i, j, t}$ and $F_{i, j, t, \Delta}$ denote the spot and $\Delta$-period (one month) forward exchange rates between currencies $i$ and $j$ at time $t$ measured in currency units of $i$ per currency unit of $j$ and $\eta_{i, t}$ is the volatility of the real pricing kernel for currency $i$ at time $t$. Asymptotic standard errors are in parentheses and the $t$-statistics are in brackets. The log likelihood function value $(L L)$ is calculated by using small sample degrees of freedom correction.

\begin{tabular}{|c|c|c|c|c|c|c|c|c|}
\hline No. & $i$ & $j$ & $c_{0}$ & $c_{2}$ & $c_{3}$ & $c_{4}$ & $c_{5}$ & $L L$ \\
\hline 1 & USD & CAD & $\begin{array}{l}0.004 \\
(0.00) \\
{[3.01]}\end{array}$ & $\begin{array}{c}-0.041 \\
(0.01) \\
{[6.20]}\end{array}$ & $\begin{array}{l}0.007 \\
(0.00) \\
{[3.95]}\end{array}$ & $\begin{array}{c}-0.008 \\
(0.00) \\
{[2.19]}\end{array}$ & $\begin{array}{c}-0.009 \\
(0.00) \\
{[3.34]}\end{array}$ & 2244.1 \\
\hline 2 & USD & DM & $\begin{array}{c}-0.044 \\
(0.04) \\
{[1.20]}\end{array}$ & $\begin{array}{l}0.342 \\
(0.10) \\
{[3.51]}\end{array}$ & $\begin{array}{l}-0.034 \\
(0.05) \\
{[0.70]}\end{array}$ & $\begin{array}{c}-0.024 \\
(0.10) \\
{[0.24]}\end{array}$ & $\begin{array}{l}0.072 \\
(0.07) \\
{[0.98]}\end{array}$ & 1755.6 \\
\hline 3 & USD & JY & $\begin{array}{c}-0.063 \\
(0.03) \\
{[2.09]}\end{array}$ & $\begin{array}{l}0.310 \\
(0.05) \\
{[5.77]}\end{array}$ & $\begin{array}{l}0.031 \\
(0.32) \\
{[0.10]}\end{array}$ & $\begin{array}{l}0.097 \\
(0.04) \\
{[2.45]}\end{array}$ & $\begin{array}{l}0.073 \\
(0.20) \\
{[0.36]}\end{array}$ & 2807.7 \\
\hline 4 & USD & $\mathrm{BP}$ & $\begin{array}{l}0.029 \\
(0.01) \\
{[3.44]}\end{array}$ & $\begin{array}{c}-0.134 \\
(0.02) \\
{[5.74]}\end{array}$ & $\begin{array}{l}0.019 \\
(0.01) \\
{[2.01]}\end{array}$ & $\begin{array}{l}0.021 \\
(0.02) \\
{[1.04]}\end{array}$ & $\begin{array}{r}-0.049 \\
(0.02) \\
{[2.54]}\end{array}$ & 2081.5 \\
\hline 5 & $\mathrm{BP}$ & CAD & $\begin{array}{c}-0.001 \\
(0.00) \\
{[0.39]}\end{array}$ & $\begin{array}{c}-0.004 \\
(0.00) \\
{[1.03]}\end{array}$ & $\begin{array}{l}-0.003 \\
(0.00) \\
{[1.45]}\end{array}$ & $\begin{array}{c}0.005 \\
(0.01) \\
{[0.78]}\end{array}$ & $\begin{array}{l}0.004 \\
(0.01) \\
{[0.73]}\end{array}$ & 1552.9 \\
\hline 6 & $\mathrm{BP}$ & DM & $\begin{array}{r}-0.002 \\
(0.01) \\
{[0.23]}\end{array}$ & $\begin{array}{r}-0.005 \\
(0.01) \\
{[0.94]}\end{array}$ & $\begin{array}{l}-0.017 \\
(0.01) \\
{[2.09]}\end{array}$ & $\begin{array}{l}0.016 \\
(0.01) \\
{[1.21]}\end{array}$ & $\begin{array}{l}0.007 \\
(0.01) \\
{[0.58]}\end{array}$ & 1272.9 \\
\hline 7 & $\mathrm{BP}$ & JY & $\begin{array}{r}-0.008 \\
(0.01) \\
{[1.10]}\end{array}$ & $\begin{array}{l}0.026 \\
(0.01) \\
{[4.40]}\end{array}$ & $\begin{array}{l}-0.399 \\
(0.09) \\
{[4.35]}\end{array}$ & $\begin{array}{r}-0.015 \\
(0.01) \\
{[1.91]}\end{array}$ & $\begin{array}{l}0.141 \\
(0.05) \\
{[2.94]}\end{array}$ & 2309.2 \\
\hline 8 & $\mathrm{BP}$ & USD & $\begin{array}{c}-0.029 \\
(0.01) \\
{[3.44]}\end{array}$ & $\begin{array}{l}-0.019 \\
(0.01) \\
{[2.01]}\end{array}$ & $\begin{array}{l}0.134 \\
(0.02) \\
{[5.74]}\end{array}$ & $\begin{array}{l}0.049 \\
(0.02) \\
{[2.54]}\end{array}$ & $\begin{array}{c}-0.021 \\
(0.02) \\
{[1.04]}\end{array}$ & 2081.5 \\
\hline
\end{tabular}


Table 9 (continued)

\begin{tabular}{|c|c|c|c|c|c|c|c|c|}
\hline No. & $i$ & $j$ & $c_{0}$ & $c_{2}$ & $c_{3}$ & $c_{4}$ & $c_{5}$ & $L L$ \\
\hline 9 & JY & CAD & $\begin{array}{l}0.023 \\
(0.01) \\
{[2.35]}\end{array}$ & $\begin{array}{l}0.203 \\
(0.07) \\
{[2.78]}\end{array}$ & $\begin{array}{c}-0.014 \\
(0.01) \\
{[2.76]}\end{array}$ & $\begin{array}{c}-0.167 \\
(0.06) \\
{[2.69]}\end{array}$ & $\begin{array}{l}0.028 \\
(0.01) \\
{[2.35]}\end{array}$ & 2289.1 \\
\hline 10 & JY & DM & $\begin{array}{c}-0.011 \\
(0.01) \\
{[1.35]}\end{array}$ & $\begin{array}{l}0.078 \\
(0.06) \\
{[1.34]}\end{array}$ & $\begin{array}{c}-0.014 \\
(0.01) \\
{[1.21]}\end{array}$ & $\begin{array}{c}-0.036 \\
(0.04) \\
{[0.95]}\end{array}$ & $\begin{array}{l}0.028 \\
(0.02) \\
{[1.66]}\end{array}$ & 1883.1 \\
\hline 11 & JY & BP & $\begin{array}{l}0.008 \\
(0.01) \\
{[1.10]}\end{array}$ & $\begin{array}{l}0.399 \\
(0.09) \\
{[4.35]}\end{array}$ & $\begin{array}{c}-0.026 \\
(0.01) \\
{[4.40]}\end{array}$ & $\begin{array}{c}-0.141 \\
(0.05) \\
{[2.94]}\end{array}$ & $\begin{array}{l}0.015 \\
(0.01) \\
{[1.91]}\end{array}$ & 2309.2 \\
\hline 12 & JY & USD & $\begin{array}{l}0.063 \\
(0.03) \\
{[2.09]}\end{array}$ & $\begin{array}{c}-0.031 \\
(0.32) \\
{[0.10]}\end{array}$ & $\begin{array}{c}-0.310 \\
(0.05) \\
{[5.77]}\end{array}$ & $\begin{array}{c}-0.073 \\
(0.20) \\
{[0.36]}\end{array}$ & $\begin{array}{r}-0.097 \\
(0.04) \\
{[2.45]}\end{array}$ & 2807.7 \\
\hline 13 & DM & CAD & $\begin{array}{c}-0.013 \\
(0.01) \\
{[2.20]}\end{array}$ & $\begin{array}{l}0.013 \\
(0.01) \\
{[1.37]}\end{array}$ & $\begin{array}{c}-0.002 \\
(0.00) \\
{[1.12]}\end{array}$ & $\begin{array}{l}0.008 \\
(0.01) \\
{[0.51]}\end{array}$ & $\begin{array}{c}-0.003 \\
(0.01) \\
{[0.56]}\end{array}$ & 1201.1 \\
\hline 14 & DM & JY & $\begin{array}{l}0.011 \\
(0.01) \\
{[1.35]}\end{array}$ & $\begin{array}{l}0.014 \\
(0.01) \\
{[1.21]}\end{array}$ & $\begin{array}{c}-0.078 \\
(0.06) \\
{[1.34]}\end{array}$ & $\begin{array}{c}-0.028 \\
(0.02) \\
{[1.66]}\end{array}$ & $\begin{array}{c}0.036 \\
(0.04) \\
{[0.95]}\end{array}$ & 1883.1 \\
\hline 15 & DM & $\mathrm{BP}$ & $\begin{array}{l}0.002 \\
(0.01) \\
{[0.23]}\end{array}$ & $\begin{array}{l}0.017 \\
(0.01) \\
{[2.09]}\end{array}$ & $\begin{array}{l}0.005 \\
(0.01) \\
{[0.94]}\end{array}$ & $\begin{array}{c}-0.007 \\
(0.01) \\
{[0.58]}\end{array}$ & $\begin{array}{c}-0.016 \\
(0.01) \\
{[1.21]}\end{array}$ & 1272.9 \\
\hline 16 & DM & USD & $\begin{array}{l}0.044 \\
(0.04) \\
{[1.20]}\end{array}$ & $\begin{array}{l}0.034 \\
(0.05) \\
{[0.70]}\end{array}$ & $\begin{array}{c}-0.342 \\
(0.10) \\
{[3.51]}\end{array}$ & $\begin{array}{c}-0.072 \\
(0.07) \\
{[0.98]}\end{array}$ & $\begin{array}{l}0.024 \\
(0.10) \\
{[0.24]}\end{array}$ & 1755.6 \\
\hline 17 & CAD & DM & $\begin{array}{l}0.013 \\
(0.01) \\
{[2.20]}\end{array}$ & $\begin{array}{l}0.002 \\
(0.00) \\
{[1.12]}\end{array}$ & $\begin{array}{c}-0.013 \\
(0.01) \\
{[1.37]}\end{array}$ & $\begin{array}{l}0.003 \\
(0.01) \\
{[0.56]}\end{array}$ & $\begin{array}{c}-0.008 \\
(0.01) \\
{[0.51]}\end{array}$ & 1201.1 \\
\hline 18 & CAD & JY & $\begin{array}{l}-0.023 \\
(0.01) \\
{[2.35]}\end{array}$ & $\begin{array}{l}0.014 \\
(0.01) \\
{[2.76]}\end{array}$ & $\begin{array}{l}-0.203 \\
(0.07) \\
{[2.78]}\end{array}$ & $\begin{array}{c}-0.028 \\
(0.01) \\
{[2.35]}\end{array}$ & $\begin{array}{l}0.167 \\
(0.06) \\
{[2.69]}\end{array}$ & 2289.1 \\
\hline 19 & CAD & $\mathrm{BP}$ & $\begin{array}{l}0.001 \\
(0.00) \\
{[0.39]}\end{array}$ & $\begin{array}{l}0.003 \\
(0.00) \\
{[1.45]}\end{array}$ & $\begin{array}{l}0.004 \\
(0.00) \\
{[1.03]}\end{array}$ & $\begin{array}{c}-0.004 \\
(0.01) \\
{[0.73]}\end{array}$ & $\begin{array}{c}-0.005 \\
(0.01) \\
{[0.78]}\end{array}$ & 1552.9 \\
\hline 20 & CAD & USD & $\begin{array}{c}-0.004 \\
(0.00) \\
{[3.01]}\end{array}$ & $\begin{array}{r}-0.007 \\
(0.00) \\
{[3.95]}\end{array}$ & $\begin{array}{l}0.041 \\
(0.01) \\
{[6.20]}\end{array}$ & $\begin{array}{l}0.009 \\
(0.00) \\
{[3.34]}\end{array}$ & $\begin{array}{l}0.008 \\
(0.00) \\
{[2.19]}\end{array}$ & 2244.1 \\
\hline
\end{tabular}


Table 10

Cointegrating Regression of log Spot Rate Change on log Forward Premium and Pricing Kernel Volatilities

The table reports the cointegrating parameter estimates for the following cointegration regressions:

$$
\ln S_{i, j, t+1}-\ln S_{i, j, t}=c_{0}+c_{1}\left(\ln F_{i, j, t, \Delta}-\ln S_{i, j, t}\right)+c_{2} \hat{\eta}_{i, t}^{2}+c_{3} \hat{\eta}_{j, t}^{2}+c_{4} \hat{\eta}_{i, t}+c_{5} \hat{\eta}_{j, t}+\epsilon
$$

where $S_{i, j, t}$ and $F_{i, j, t, \Delta}$ denote the spot and $\Delta$-period (one month) forward exchange rates between currencies $i$ and $j$ at time $t$ measured in currency units of $i$ per currency unit of $j$ and $\eta_{i, t}$ is the volatility of the real pricing kernel for currency $i$ at time $t$. Asymptotic standard errors are in parentheses and the t-statistics are in brackets. The log likelihood function value $(L L)$ is calculated by using small sample degrees of freedom correction.

\begin{tabular}{|c|c|c|c|c|c|c|c|c|c|}
\hline No. & $i$ & $j$ & $c_{0}$ & $c_{1}$ & $c_{2}$ & $c_{3}$ & $c_{4}$ & $c_{5}$ & $L L$ \\
\hline 1 & USD & CAD & $\begin{array}{l}0.001 \\
(0.00) \\
{[0.77]}\end{array}$ & $\begin{array}{c}-0.214 \\
(0.89) \\
{[0.24]}\end{array}$ & $\begin{array}{c}-0.033 \\
(0.01) \\
{[5.81]}\end{array}$ & $\begin{array}{l}0.005 \\
(0.00) \\
{[3.33]}\end{array}$ & $\begin{array}{c}-0.009 \\
(0.00) \\
{[2.52]}\end{array}$ & $\begin{array}{c}-0.005 \\
(0.00) \\
{[1.61]}\end{array}$ & 3294.9 \\
\hline 2 & USD & DM & $\begin{array}{l}0.030 \\
(0.03) \\
{[1.15]}\end{array}$ & $\begin{array}{c}15.746 \\
(5.09) \\
{[3.09]}\end{array}$ & $\begin{array}{l}0.060 \\
(0.06) \\
{[1.03]}\end{array}$ & $\begin{array}{l}0.000 \\
(0.02) \\
{[0.01]}\end{array}$ & $\begin{array}{l}0.105 \\
(0.06) \\
{[1.77]}\end{array}$ & $\begin{array}{c}-0.053 \\
(0.05) \\
{[1.06]}\end{array}$ & 2610.6 \\
\hline 3 & USD & JY & $\begin{array}{l}0.021 \\
(0.01) \\
{[1.95]}\end{array}$ & $\begin{array}{c}-3.349 \\
(3.24) \\
{[1.03]}\end{array}$ & $\begin{array}{c}-0.073 \\
(0.02) \\
{[3.68]}\end{array}$ & $\begin{array}{r}-0.052 \\
(0.11) \\
{[0.50]}\end{array}$ & $\begin{array}{r}-0.037 \\
(0.02) \\
{[2.19]}\end{array}$ & $\begin{array}{l}0.008 \\
(0.07) \\
{[0.12]}\end{array}$ & 3783.1 \\
\hline 4 & USD & $\mathrm{BP}$ & $\begin{array}{l}0.035 \\
(0.02) \\
{[1.72]}\end{array}$ & $\begin{array}{l}2.630 \\
(5.17) \\
{[0.51]}\end{array}$ & $\begin{array}{r}-0.137 \\
(0.03) \\
{[4.69]}\end{array}$ & $\begin{array}{l}0.019 \\
(0.01) \\
{[2.05]}\end{array}$ & $\begin{array}{l}0.034 \\
(0.04) \\
{[0.91]}\end{array}$ & $\begin{array}{r}-0.052 \\
(0.02) \\
{[2.42]}\end{array}$ & 3157.0 \\
\hline 5 & $\mathrm{BP}$ & CAD & $\begin{array}{c}0.005 \\
(0.00) \\
{[1.36]}\end{array}$ & $\begin{array}{c}-3.383 \\
(1.94) \\
{[1.75]}\end{array}$ & $\begin{array}{c}-0.006 \\
(0.00) \\
{[1.67]}\end{array}$ & $\begin{array}{c}-0.002 \\
(0.00) \\
{[1.21]}\end{array}$ & $\begin{array}{l}0.008 \\
(0.01) \\
{[1.34]}\end{array}$ & $\begin{array}{l}0.001 \\
(0.00) \\
{[0.17]}\end{array}$ & 2523.4 \\
\hline 6 & $\mathrm{BP}$ & DM & $\begin{array}{c}-0.012 \\
(0.01) \\
{[1.50]}\end{array}$ & $\begin{array}{l}6.510 \\
(1.38) \\
{[4.72]}\end{array}$ & $\begin{array}{c}-0.005 \\
(0.01) \\
{[0.87]}\end{array}$ & $\begin{array}{c}-0.006 \\
(0.01) \\
{[0.71]}\end{array}$ & $\begin{array}{l}0.035 \\
(0.01) \\
{[2.41]}\end{array}$ & $\begin{array}{r}-0.032 \\
(0.02) \\
{[1.91]}\end{array}$ & 2171.0 \\
\hline 7 & $\mathrm{BP}$ & JY & $\begin{array}{l}0.290 \\
(0.04) \\
{[7.20]}\end{array}$ & $\begin{array}{c}-48.181 \\
(6.40) \\
{[7.53]}\end{array}$ & $\begin{array}{l}0.047 \\
(0.01) \\
{[3.41]}\end{array}$ & $\begin{array}{r}-0.116 \\
(0.21) \\
{[0.54]}\end{array}$ & $\begin{array}{r}-0.066 \\
(0.02) \\
{[3.58]}\end{array}$ & $\begin{array}{r}-0.166 \\
(0.11) \\
{[1.44]}\end{array}$ & 3286.2 \\
\hline 8 & $\mathrm{BP}$ & USD & $\begin{array}{c}-0.035 \\
(0.02) \\
{[1.72]}\end{array}$ & $\begin{array}{c}2.63 \\
(5.17) \\
{[0.51]}\end{array}$ & $\begin{array}{c}-0.019 \\
(0.01) \\
{[2.05]}\end{array}$ & $\begin{array}{l}0.137 \\
(0.03) \\
{[4.69]}\end{array}$ & $\begin{array}{l}0.052 \\
(0.02) \\
{[2.42]}\end{array}$ & $\begin{array}{c}-0.034 \\
(0.04) \\
{[0.91]}\end{array}$ & 3157.0 \\
\hline
\end{tabular}


Table 10 (continued)

\begin{tabular}{|c|c|c|c|c|c|c|c|c|c|}
\hline No. & $i$ & $j$ & $c_{0}$ & $c_{1}$ & $c_{2}$ & $c_{3}$ & $c_{4}$ & $c_{5}$ & $L L$ \\
\hline 9 & JY & CAD & $\begin{array}{l}0.013 \\
(0.01) \\
0.98]\end{array}$ & $\begin{array}{l}-2.385 \\
(1.97) \\
{[1.21]}\end{array}$ & $\begin{array}{l}0.210 \\
(0.08) \\
{[2.79]}\end{array}$ & $\begin{array}{l}-0.014 \\
(0.01) \\
{[2.62]}\end{array}$ & $\begin{array}{l}-0.173 \\
(0.06) \\
{[2.70]}\end{array}$ & $\begin{array}{l}0.027 \\
(0.01) \\
{[2.21]}\end{array}$ & 3217.9 \\
\hline 10 & JY & $\mathrm{DM}$ & $\begin{array}{l}-0.032 \\
(0.01) \\
{[2.59]}\end{array}$ & $\begin{array}{l}-4.418 \\
(2.46) \\
{[1.80]}\end{array}$ & $\begin{array}{l}0.005 \\
(0.06) \\
{[0.09]}\end{array}$ & $\begin{array}{l}-0.019 \\
(0.01) \\
{[1.66]}\end{array}$ & $\begin{array}{l}-0.021 \\
(0.04) \\
{[0.56]}\end{array}$ & $\begin{array}{l}0.054 \\
(0.02) \\
{[2.56]}\end{array}$ & 2698.0 \\
\hline 11 & JY & $\mathrm{BP}$ & $\begin{array}{l}-0.290 \\
(0.04) \\
{[7.20]}\end{array}$ & $\begin{array}{c}-48.181 \\
(6.40) \\
{[7.53]}\end{array}$ & $\begin{array}{l}0.116 \\
(0.21) \\
{[0.54]}\end{array}$ & $\begin{array}{l}-0.047 \\
(0.01) \\
{[3.41]}\end{array}$ & $\begin{array}{l}0.166 \\
(0.11) \\
{[1.44]}\end{array}$ & $\begin{array}{l}0.066 \\
(0.02) \\
{[3.58]}\end{array}$ & 3286.2 \\
\hline 12 & JY & USD & $\begin{array}{c}-0.021 \\
(0.01) \\
{[1.95]}\end{array}$ & $\begin{array}{l}-3.349 \\
(3.24) \\
{[1.03]}\end{array}$ & $\begin{array}{l}0.052 \\
(0.11) \\
{[0.50]}\end{array}$ & $\begin{array}{l}0.073 \\
(0.02) \\
{[3.68]}\end{array}$ & $\begin{array}{c}-0.008 \\
(0.07) \\
{[0.12]}\end{array}$ & $\begin{array}{l}0.037 \\
(0.02) \\
{[2.19]}\end{array}$ & 3783.1 \\
\hline 13 & DM & CAD & $\begin{array}{l}-0.010 \\
(0.01) \\
{[1.39]}\end{array}$ & $\begin{array}{l}-2.320 \\
(1.83) \\
{[1.27]}\end{array}$ & $\begin{array}{l}0.009 \\
(0.01) \\
{[0.90]}\end{array}$ & $\begin{array}{l}-0.006 \\
(0.00) \\
{[2.25]}\end{array}$ & $\begin{array}{l}0.003 \\
(0.02) \\
{[0.17]}\end{array}$ & $\begin{array}{l}0.004 \\
(0.01) \\
{[0.60]}\end{array}$ & 2012.4 \\
\hline 14 & $\mathrm{DM}$ & JY & $\begin{array}{l}0.032 \\
(0.01) \\
{[2.59]}\end{array}$ & $\begin{array}{l}-4.418 \\
(2.46) \\
{[1.80]}\end{array}$ & $\begin{array}{l}0.019 \\
(0.01) \\
{[1.66]}\end{array}$ & $\begin{array}{l}-0.005 \\
(0.06) \\
{[0.09]}\end{array}$ & $\begin{array}{l}-0.054 \\
(0.02) \\
{[2.56]}\end{array}$ & $\begin{array}{l}0.021 \\
(0.04) \\
{[0.56]}\end{array}$ & 2698.0 \\
\hline 15 & $\mathrm{DM}$ & BP & $\begin{array}{l}0.012 \\
(0.01) \\
{[1.50]}\end{array}$ & $\begin{array}{l}6.510 \\
(1.38) \\
{[4.72]}\end{array}$ & $\begin{array}{l}0.006 \\
(0.01) \\
{[0.71]}\end{array}$ & $\begin{array}{l}0.005 \\
(0.01) \\
{[0.87]}\end{array}$ & $\begin{array}{l}0.032 \\
(0.02) \\
{[1.91]}\end{array}$ & $\begin{array}{l}-0.035 \\
(0.01) \\
{[2.41]}\end{array}$ & 2171.0 \\
\hline 16 & $\mathrm{DM}$ & USD & $\begin{array}{l}-0.030 \\
(0.03) \\
{[1.15]}\end{array}$ & $\begin{array}{l}15.746 \\
(5.09) \\
{[3.09]}\end{array}$ & $\begin{array}{l}0.000 \\
(0.02) \\
{[0.01]}\end{array}$ & $\begin{array}{l}-0.060 \\
(0.06) \\
{[1.03]}\end{array}$ & $\begin{array}{l}0.053 \\
(0.05) \\
{[1.06]}\end{array}$ & $\begin{array}{l}-0.105 \\
(0.06) \\
{[1.77]}\end{array}$ & 2610.6 \\
\hline 17 & CAD & $\mathrm{DM}$ & $\begin{array}{l}0.010 \\
(0.01) \\
{[1.39]}\end{array}$ & $\begin{array}{l}-2.320 \\
(1.83) \\
{[1.27]}\end{array}$ & $\begin{array}{l}0.006 \\
(0.00) \\
{[2.25]}\end{array}$ & $\begin{array}{l}-0.009 \\
(0.01) \\
{[0.90]}\end{array}$ & $\begin{array}{l}-0.004 \\
(0.01) \\
{[0.60]}\end{array}$ & $\begin{array}{l}-0.003 \\
(0.02) \\
{[0.17]}\end{array}$ & 2012.4 \\
\hline 18 & CAD & JY & $\begin{array}{l}-0.013 \\
(0.01) \\
{[0.98]}\end{array}$ & $\begin{array}{l}-2.385 \\
(1.97) \\
{[1.21]}\end{array}$ & $\begin{array}{l}0.014 \\
(0.01) \\
{[2.62]}\end{array}$ & $\begin{array}{l}-0.210 \\
(0.08) \\
{[2.79]}\end{array}$ & $\begin{array}{l}-0.027 \\
(0.01) \\
{[2.21]}\end{array}$ & $\begin{array}{l}0.173 \\
(0.06) \\
{[2.70]}\end{array}$ & 3217.9 \\
\hline 19 & CAD & BP & $\begin{array}{l}-0.005 \\
(0.00) \\
{[1.36]}\end{array}$ & $\begin{array}{l}-3.383 \\
(1.94) \\
{[1.75]}\end{array}$ & $\begin{array}{l}0.002 \\
(0.00) \\
{[1.21]}\end{array}$ & $\begin{array}{l}0.006 \\
(0.00) \\
{[1.67]}\end{array}$ & $\begin{array}{l}-0.001 \\
(0.00) \\
{[0.17]}\end{array}$ & $\begin{array}{l}-0.008 \\
(0.01) \\
{[1.34]}\end{array}$ & 2523.4 \\
\hline 20 & CAD & USD & $\begin{array}{l}-0.001 \\
(0.00) \\
{[0.77]}\end{array}$ & $\begin{array}{l}-0.214 \\
(0.89) \\
{[0.24]}\end{array}$ & $\begin{array}{l}-0.005 \\
(0.00) \\
{[3.33]}\end{array}$ & $\begin{array}{l}0.033 \\
(0.01) \\
{[5.81]}\end{array}$ & $\begin{array}{l}0.005 \\
(0.00) \\
{[1.61]}\end{array}$ & $\begin{array}{l}0.009 \\
(0.00) \\
{[2.52]}\end{array}$ & 3294.9 \\
\hline
\end{tabular}


Figure 1

Time Series of Real Interest Rate Estimates

The figure plots the estimated real interest rate for the United States, Canada, the United Kingdom, Germany and Japan from January 1985 to May 2002. The series are filtered out from the bond yield and Inflation data.
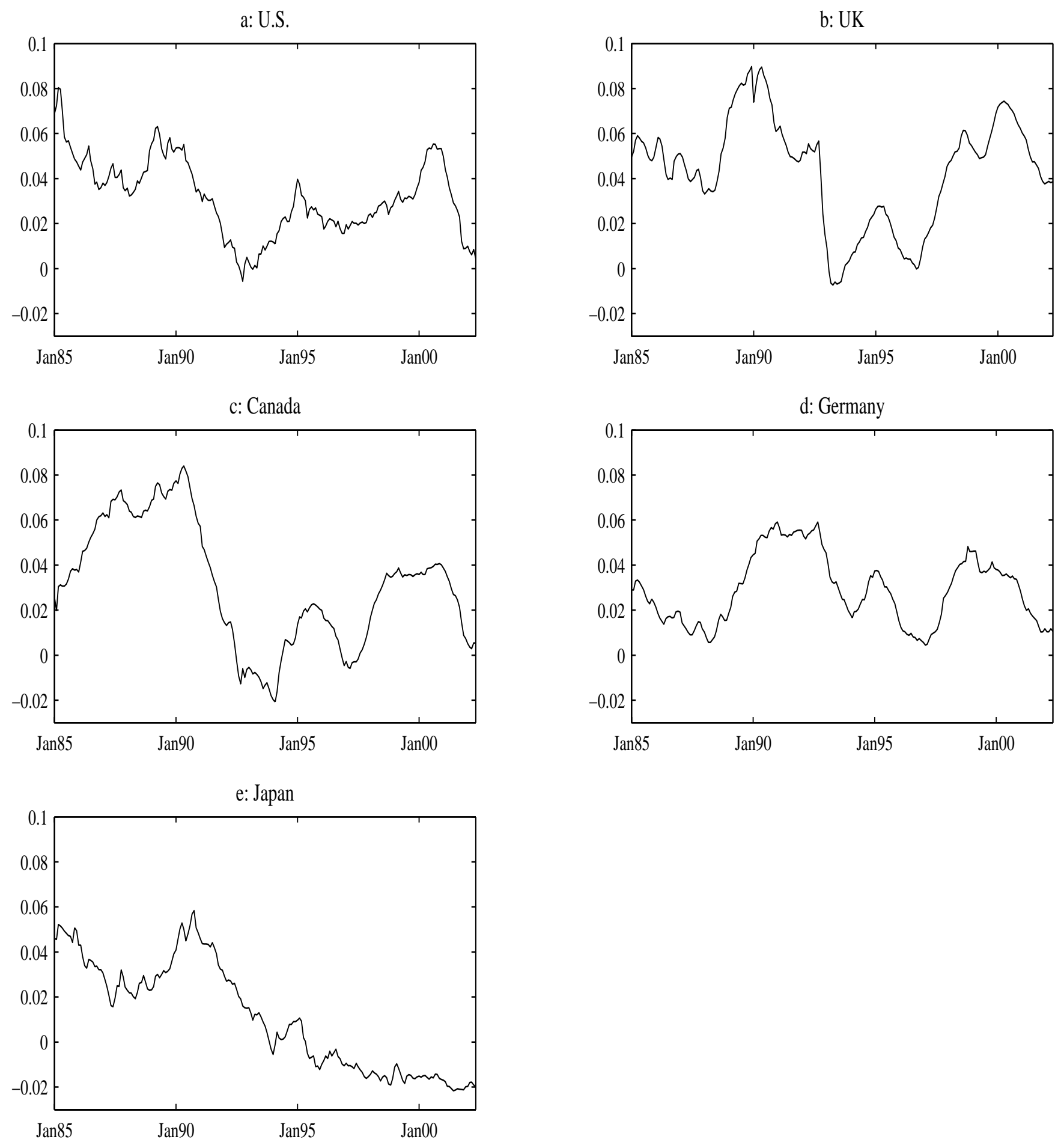
Figure 2

Time Series of Expected Inflation Estimates

The figure plots the estimated expected Inflation for the United States, Canada, the United Kingdom, Germany and Japan from January 1985 to May 2002. The series are filtered out from the bond yield and Inflation data.
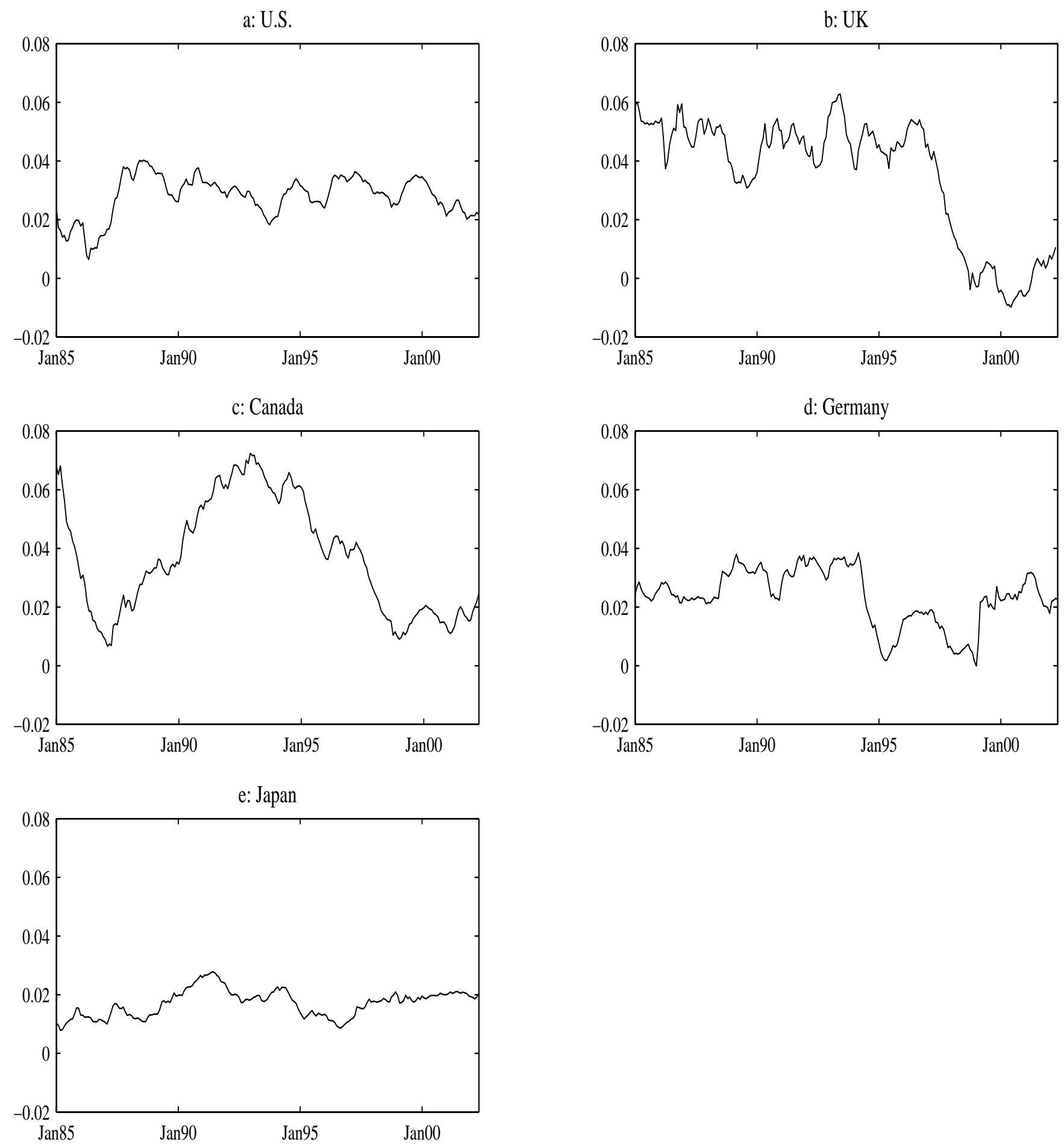
Figure 3

Time Series of Maximum Sharpe Ratio Estimates

The figure plots the estimated Sharpe ratio for the United States, Canada, the United Kingdom, Germany and Japan from January 1985 to May 2002. The series are filtered out from the bond yield and Inflation data.

a: U.S.

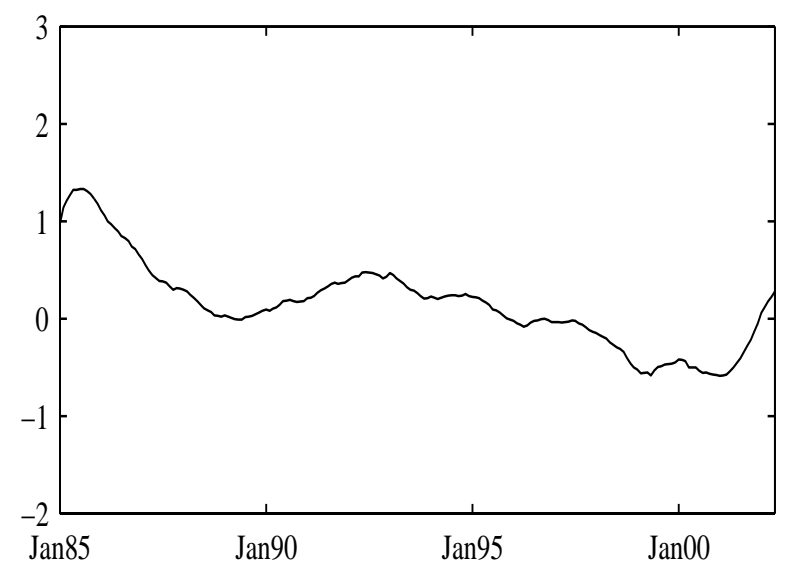

c: Canada

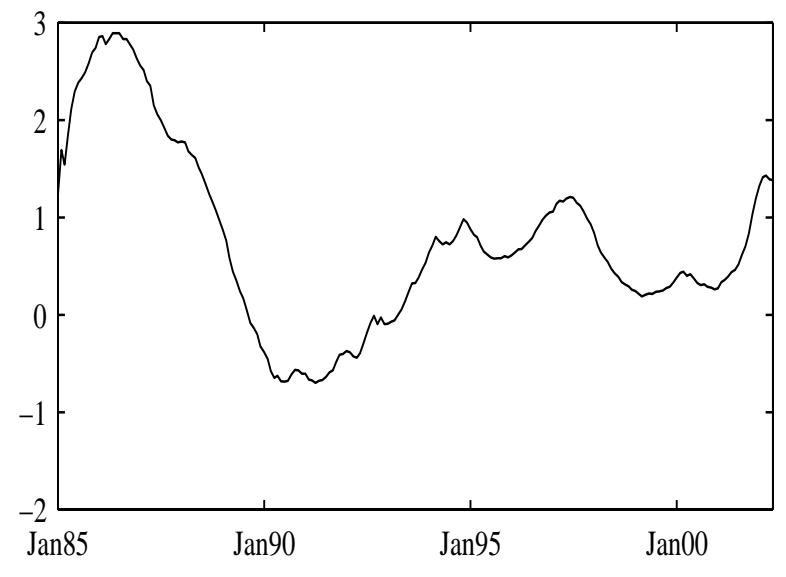

e: Japan

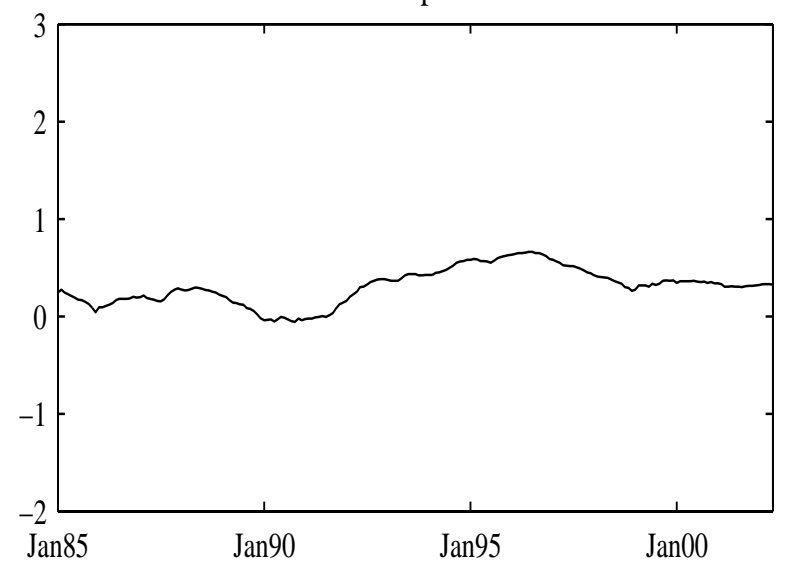

b: UK

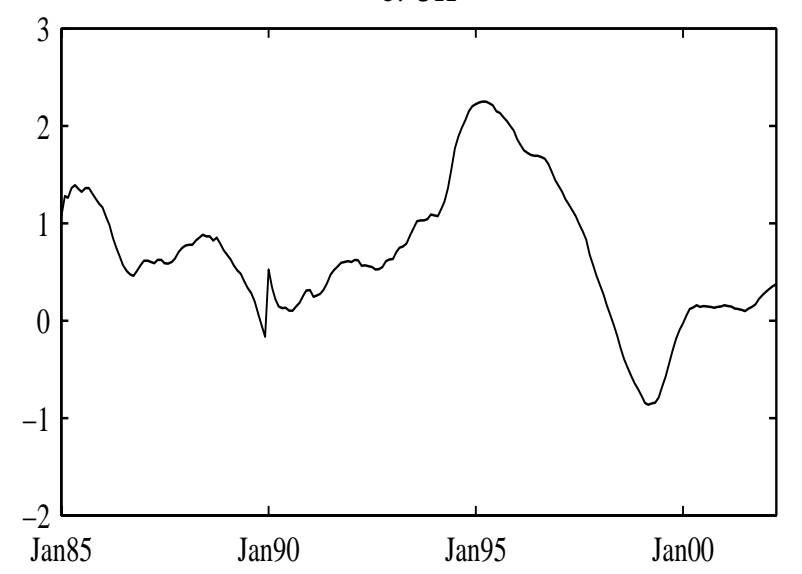

d: Germany

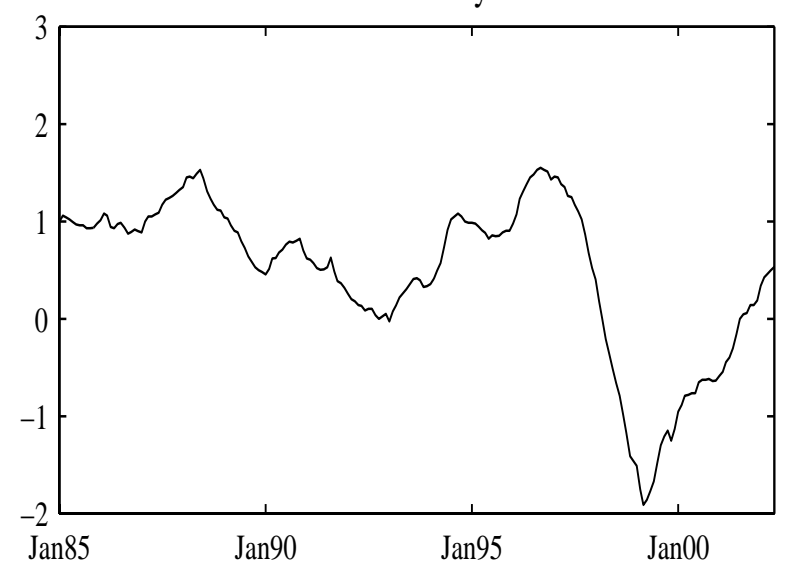

